\title{
Best Practices in Data Driven Development Planning in Mining Regions
}

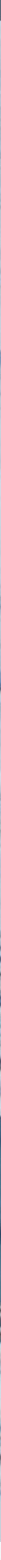

JUNE 2020

Nicolas Maennling \& Josefina Correa
จ. Columbia Center on Sustainable Investment A JOINT CENTER OF COLUMBIA LAW SCHOOL 


\section{Acknowledgments}

The authors would like to thank Verena Egetemeir and Tracey Cooper for their valuable contributions with case studies. Thanks also to Perrine Toledano and Nancy Siporin for their thorough review. The work would not have been possible without the collaboration with AMSA and NuevaUnión.

\section{Table of Contents}

\section{Introduction}

\section{Why it is important to plan}

3. What a development strategy should include

4. Integrating the sustainable development goals in sustainable development strategies

5. Interaction and alignment of development strategies

\section{Process to develop a development strategy}

\subsection{Diagnosis of the territory: An inclusive assessment}

\subsection{Defining objectives, goals and targets}

\subsection{Setting up a monitoring and evaluation system}

\section{Conclusion}

Annex: Case studies of tools and resources

\section{Introduction}

The world is entering an era where data is generated and used at an unprecedented scale. Technologies to collect real-time data are increasingly available at low cost. This data abundance can be used to improve policy decision making and increase transparency to hold stakeholders accountable. CCSI has been working to support mining-impacted regions to develop consultative long-term strategies that aim to achieve the Sustainable Development Goals (SDGs). The inclusion of quantitative targets that are adapted to the region's specificities, and the design of transparent and data-driven monitoring and evaluation systems, have been key components of these projects. This report summarizes the best practices of data-driven development planning and provides case studies and examples of data-based monitoring tools.

The report is structured as follows: Section 2 provides background as to why it is important to plan and prepare long-term development strategies that guide investments and policy decisions. Section 3 outlines, in broad terms, what a longterm development strategy should entail. Section 4 explains why the Sustainable Development Goal (SDG) framework is a useful tool to support development planning and monitoring. Section 5 outlines how various planning instruments should align and interact to be implemented efficiently. Section 6 provides a step-by-step overview of the process that is needed to implement a successful development planning and monitoring framework. Two case studies from Chile are featured where CCSI worked together with Dinamica Plataforma and the Center for International Earth Science Information Network (CIESIN) to implement parts of such a process. The NuevaUnión project provides a good example of how to develop a roadmap for a long-term development plan around a mine site in a participatory manner. The Los Pelambres mining project has implemented an SDG-based monitoring tool that tracks development interventions and indicators in Choapa Province. 
The last section concludes by summarizing the importance of data-driven planning and monitoring systems to improve development outcomes on the ground and ways in which mining companies can support such efforts. Examples of data-based tools from other sectors and jurisdictions are provided in the annex to showcase how technologies can be used to get a better and more timely understanding of the development needs of a region, how data sources can be compiled to better inform policymakers, and how transparency of these monitoring tools can help increase accountability.

\section{Why it is important to plan}

Development strategies have long been used by companies and governments alike to guide actions and investments in the medium to long-term. It is important to distinguish between a long-term development strategy and a planned economy. The former sets out where a country/region wants to be in the long-term regarding development outcomes, highlighting areas that are best placed to help reach those outcomes. The latter is a more detailed assessment focusing primarily on economic aspects, namely how capital can be accumulated. Throughout this document we refer to the former type of strategy. The 1998 Prebish Lecture by Joseph Stiglitz provides strong arguments regarding the benefits of long-term development strategies as compared to approaches that were largely advised and implemented during the Washington Consensus years (particularly in Latin America). ${ }^{1}$
The benefits of long-term development strategies include:

- Consensus building about goals and priorities: The process of coming up with a long-term development strategy is just as important as the strategy itself. A consultative process is necessary to develop a longterm vision with associated goals and targets. This process can help stakeholders to voice opinions and constructively argue about what the country or region should look like in 20-30 years. Such a process can create societal bonds and help ensure that a common goal is pursued by actors within a country/region.

- Continuity beyond political and project cycles: Public investments have long lead times and take time to result in development outcomes - often beyond election cycles and large-scale private investments. Furthermore, it is important that policies build on previous achievements. While mediumterm plans that follow the election cycles (4-6 years) are important to lay out concrete policy actions and expenditure frameworks, the vision and goals of the long-term strategy can provide guidance regarding what should be prioritized. Interventions should also go beyond private sector project investment timeframes, as this will be needed to ensure sustainability once the private sector investment ceases to exist. To ensure continuity beyond political cycles it is therefore of importance that the consultative process of the long-term development strategy includes all stakeholders in the impacted region, including the political opposition. Without such an inclusive process, there is a risk that longterm development strategies are re-written by each incoming government or private sector investment, resulting, instead, in medium-term plans. 
- Coherence among government ministries, donors, private sector, and civil society stakeholders: Achieving development outcomes is complex and requires a combination of interventions to be successful. Reducing the poverty rate, for example, requires policy interventions and investments in different areas that are the responsibility of various ministries. Furthermore, economies of scale can be achieved by coordinating investments thereby leading to improved outcomes as compared to each ministry following different objectives. The longterm development strategy can serve as an umbrella guideline to the ministries, with each sector assessing how it can contribute to the vision and long-term goals. Sectoral strategies should also align with the long-term development strategy. Private sector, donor, and civil society interventions should build on and be closely aligned with government plans and intervention to maximize efficiency and avoid duplication of efforts.

- Vertical coherence: Apart from guiding roles and responsibilities across government institutions and relevant stakeholders, it is also critical to coordinate the actions of the national and sub-national entities. The long-term development strategies at the various levels of government should be aligned with each other, assigning roles and responsibilities according to who is responsible for implementation to avoid duplicating efforts. The same is true for large multinationals that may have global, national, and local offices that require coordination.

Particularly for resource-rich countries/regions where mining is one of the driving economic activities, longterm development strategies are essential. First, a long-term development strategy can help to provide coherence among stakeholders. Mining companies, particularly large-scale operations, often spend significant resources at the local level. Aligning these investments with those of the government will help achieve better development outcomes.

Second, the volatile nature of the commodity sector can translate into volatility within the local economy. New investments, particularly those in large-scale mining operations, can result in an influx of workers, put additional pressure on government services, and lead to local inflation. In jurisdictions where a portion of the royalties are paid or transferred to local governments, mining production and commodity price volatility can result in large local government budget increases and volatility; which, in turn, may lead to inefficient spending and corruption. ${ }^{2}$ Such impacts can be better managed if planned for in advance.

Third, the mining sector often attracts the most qualified labor resources with higher wages. Other sectors in the economy can suffer, leading to an even greater reliance on mining. Diversification efforts by the government are therefore of critical importance.

Fourth, mining investments are politicized with high stakes in terms of potential economic benefits and environmental costs. This can lead to distrust among stakeholders in a region and result in conflict. Therefore, agreeing on the role of mining in a long-term development strategy upfront can help create consensus regarding what role mining should play in the region's economic development and under what conditions large-scale investments should be welcomed. Furthermore, territorial planning can help to determine what areas should be reserved to conserve the natural and cultural heritage.

\section{What a development strategy should include}

While the specifics of what should be included in a longterm development strategy will be context specific, sustainable development is achieved through investments in six forms of capital. These should be addressed in the strategy and include: (1) Business capital, which includes private sector activities in the agriculture, extractives, industrial, and services sectors; (2) infrastructure, which includes investments in transport, power, water, sanitation, and telecommunications; (3) human capital, which ensures the health and education of the workforce; (4) intellectual capital to support scientific and technological know-how; (5) natural capital, which protects the ecosystems; and (6) social capital which fosters communal trust and good governance. These forms of capital are closely interlinked. Natural capital, for example, is necessary to support business activities in the agriculture sector and to ensure a healthy workforce. In turn, without a healthy workforce or infrastructure, business investments cannot be profitable.

All stakeholders have a role to play. The private sector will be the driving force for the business capital investments. The government plays a key role in the human capital investments and in ensuring that market failures do not occur that harm the natural capital. Civil society plays a key role in driving the social capital to require transparency and hold the government and companies accountable. In other areas such as infrastructure capital, there are opportunities to leverage public and private investments and create economies of scale. 


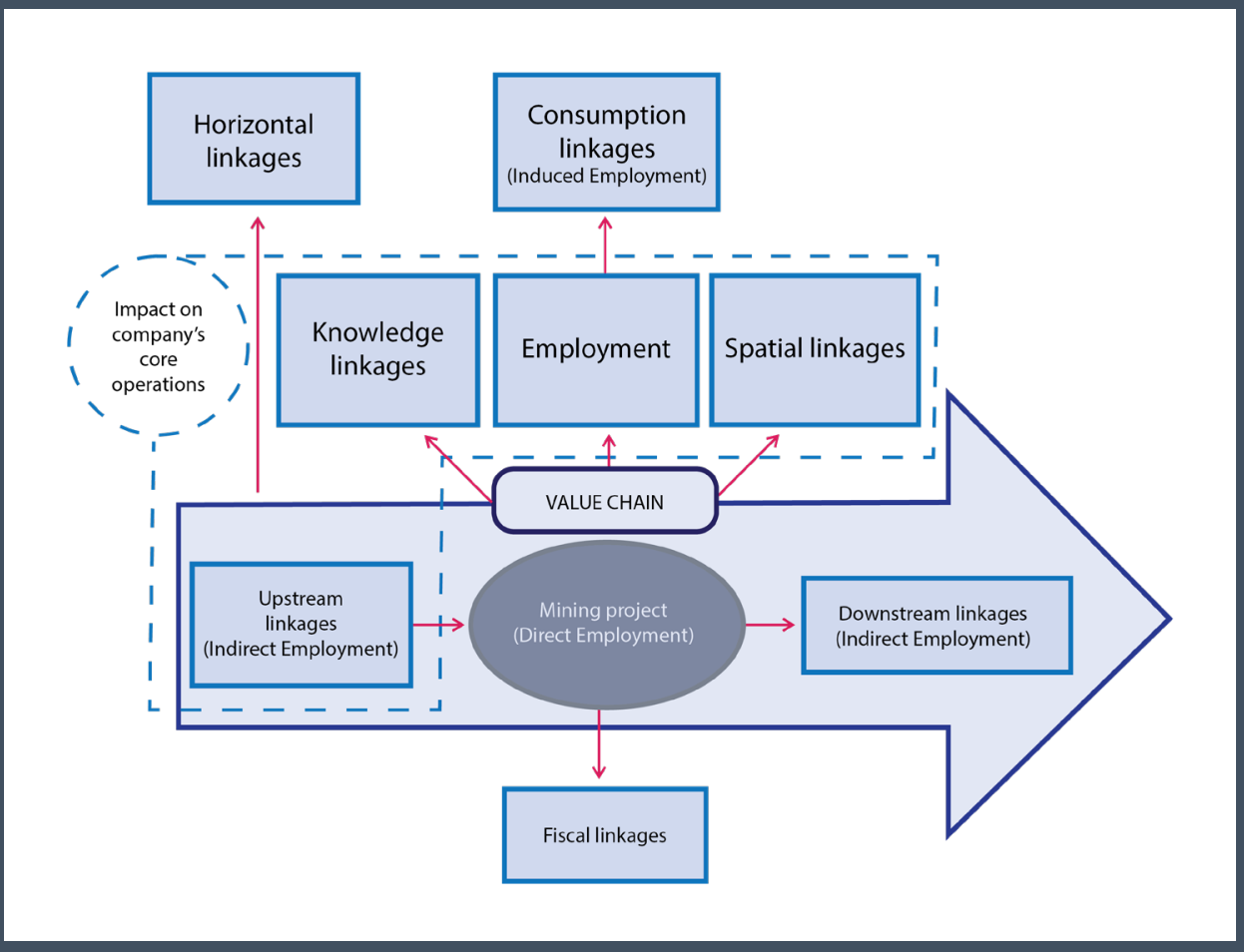

Source: CCSI (2016) Linkages to the Resource Sector ${ }^{14}$
The economic sectors that are thought to be the drivers of the business capital investment should be featured in the long-term development strategy. As such, in mineral rich regions, the mining sector should be featured. Apart from addressing the role that the sector is going to play and how to ensure a balance between the business and particularly the natural capitals, the potential positive linkages from the sector should be assessed. Figure 1 outlines these potential positive linkages to the economy that could lead to additional capital investments and help the region to diversify from mining.

\section{These include:}

Fiscal linkages, that refer to the payments - such as royalties - that mining companies make to governments in order to extract and sell the resources.

Upstream linkages, that relate to the procurement of goods and services that the mining sector requires to operate. For example, this includes welding services needed to maintain equipment.
Downstream linkages, that relate to the beneficiation of extracted commodities through refining, smelting, and further downstream processing of the commodity before reaching the final consumer. For example, $98 \%$ of the world's mined iron ore is used to make steel and therefore needs to pass through a steel mill.

Horizontal linkages, that relate to the development of new industries using the capabilities of the El-related supply chain. Apart from originating from the mining project, horizontal linkages can occur from the upstream and downstream levels. For example, mining trucks could be re-engineered and adapted to service the logging industry.

Consumption linkages, that relate to the demand for goods and services resulting from the spending of earnings from the El sector. For example, when a truck driver employed to work at a mine site spends his salary on buying construction materials to build a family house. 


\section{Figure 2: Potential negative impacts from the mining sector}

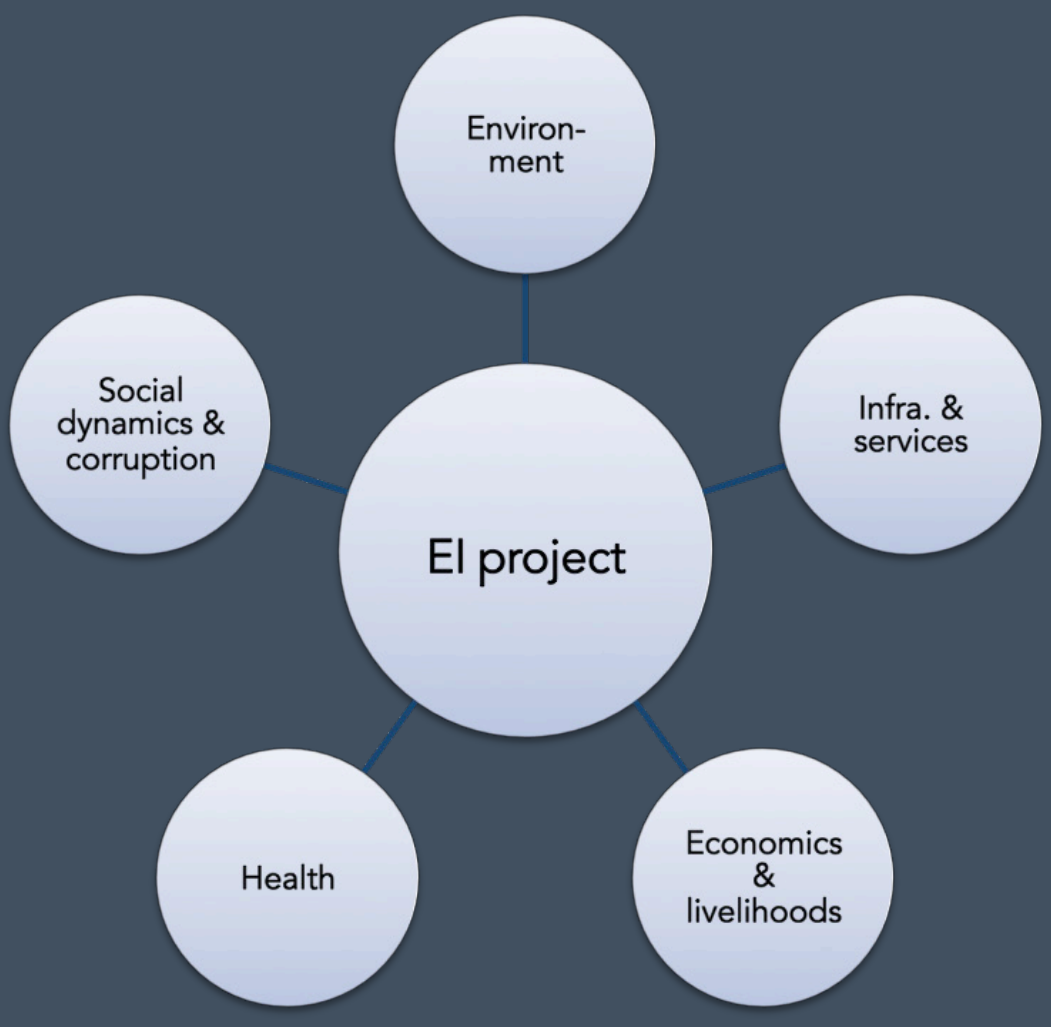

Source: Authors

Knowledge linkages, that relate to the transfer of knowledge and technological know-how. For example, a mining company may require IT services with higher expertise. Apart from benefitting the mining company itself, the developed IT expertise may also benefit other sectors in the economy.

Spatial linkages, that relate to the benefits associated with the infrastructure developed for a mining project profiting other actors in the economy. For example, a copper mine is likely going to require water infrastructure. Other users from the mining sector and non-mining sector may benefit from this water infrastructure if granted access.

Upstream, downstream, and fiscal linkages are linked with the project itself. Horizontal, knowledge, and spatial linkages can originate from the whole value chain. Consumption linkages originate from the spending of employees from the mining project itself (direct employment) and the upstream and downstream businesses (indirect employment). The dotted line in Figure 1 represents those linkages that feed directly into the core operation of the project. This is of importance because it indicates whether it is in the self-interest of the company to develop that particular linkage (domestically or internationally). For example, it is in the self-interest of a mining company to procure high quality goods and services from upstream companies, and therefore it may consider support programs that help transfer knowledge to meet these standards. However, the company is less likely to be concerned about potential developments in unrelated sectors of the economy, and therefore the support of horizontal linkages would have to be government driven. While consumption linkages are not related to the core business of the El company, they might be in the company's self-interest to the extent that they might contribute to receiving and retaining its social license to operate. ${ }^{3}$

Apart from assessing the potential positive opportunities resulting from mining investments, the potential negative externalities should also be reviewed with the aim of mitigating or managing the impacts. Figure 2 outlines some of the externalities that can be expected.

These include negative impacts on the natural capital; increased pressure on local infrastructure and services as a result of immigration; changing economic structures and impacts on livelihoods (for example, for those people that are displaced by the mining project or that relied on 
Figure 3: The Sustainable Development Goals

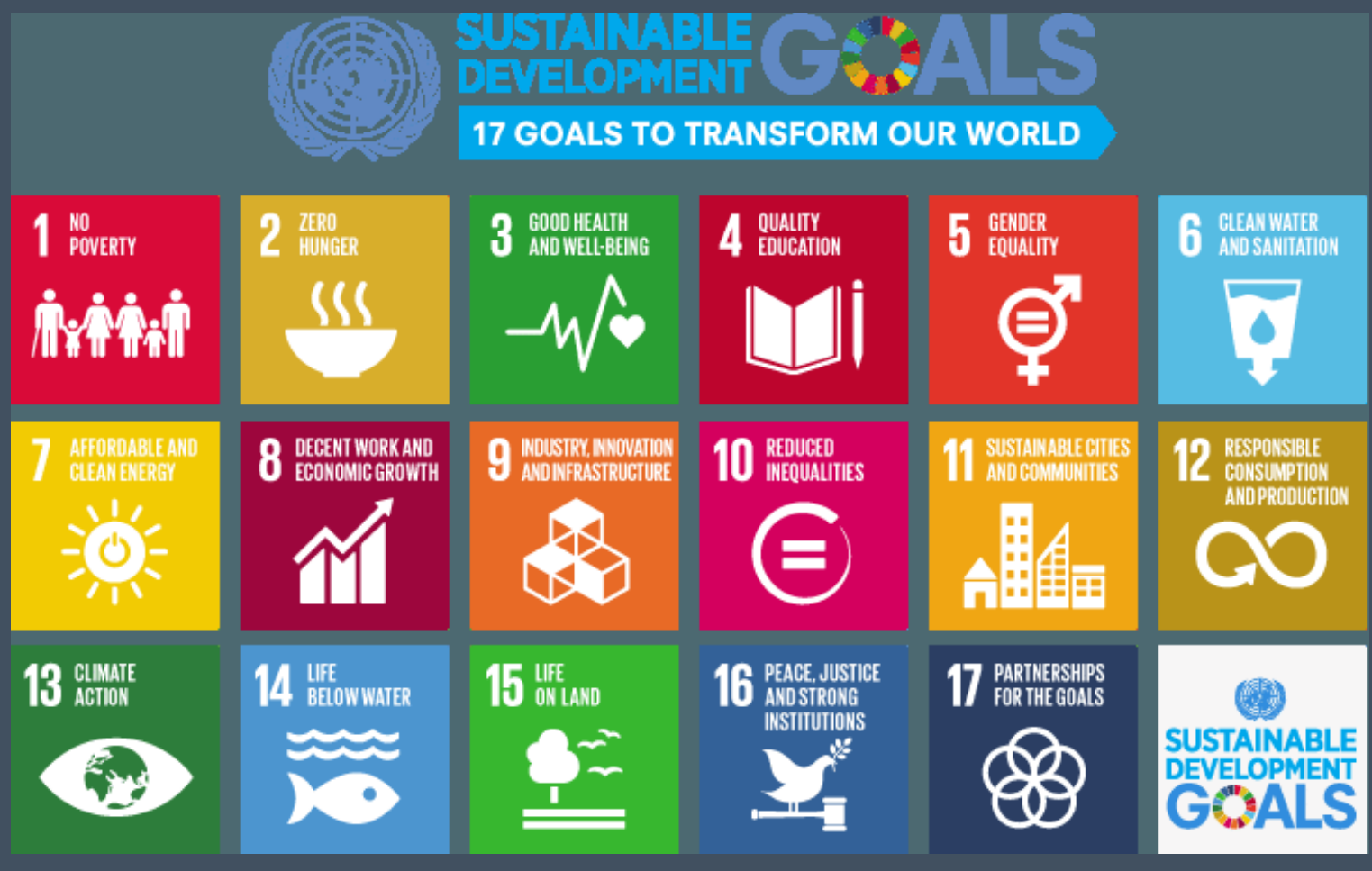

Source: United Nations

the land on which the mining project is installed); adverse health impacts from air, water, and noise pollution, as well as new diseases that may result from immigration; and changing social dynamics.

While best practices foresee that a long-term development strategy should include aspects of the business, capital, infrastructure, human capital, intellectual capital, and natural capital, the details are very context specific. Even in mining jurisdictions, where the above outlined positive and negative externalities should be reviewed, the ultimate focus of how the sector can contribute and how to mitigate/manage negative externalities will be very commodity, context, and project specific. For example, for a large-scale copper mining project in an arid region, there may be opportunities and risks associated with water use; for a bulk commodity mining project, there may be opportunities and risks associated with transport infrastructure; and for a gold mining project, there may be opportunities and risks associated with artisanal mining.

\section{Integrating the sustainable development goals in sustainable development strategies}

In September 2015, world leaders adopted the new sustainable development agenda for the following 30 years. The Agenda 2030 foresees that all countries strive to achieve the 17 Sustainable Development Goals (SDGs) shown in Figure 3.

This framework builds on the Millennium Development Goals (MDGs) used during the previous 15 years. The SDG framework is characterized by being: ${ }^{4}$

(1) Ambitious: seeking to, for example, eliminate poverty;

(2) Universal: with greater focus on inclusive development and planetary boundaries, thereby also applying to developed countries rather than primarily developing countries (as was the case with the MDGs);

(3) Multi-dimensional: not only addressing social and economic challenges, but also environmental and good governance issues;

(4) Holistic: goals are interconnected, covering the most pressing global challenges; 
(5) Constantly revised and expanded: linked to major international agreements such as the Paris Climate Agreement and the New Urban Agenda;

(6) Inclusive: depending on the support of all stakeholders including the private sector;

(7) Measurable: providing a set of indicators and targets that can be easily adopted and adapted by any organization.
These characteristics of the SDG framework are useful for developing a long-term development strategy, as they provide a common language of what development means and suggest ways to measure development. The SDGs have 169 targets and 232 indicators to measure progress. This is not to say that only the SDG framework should be used to define and measure progress in the context of a local long-term development strategy, as context matters and indicators should be adapted accordingly. However, the SDG framework does provide a good starting point, given the several years dedicated to developing its indicators, as well as it being based on numerous expert reviews and assessments of what data is obtainable in most jurisdictions.

The SDG framework also puts great focus on private sector contribution to the development agenda-something that companies and the mining sector have been quick to adopt (Box 1).

\section{Box 1: Private sector contributions to the SDGs}

Since the adoption of the SDGs in 2015, the private sector has increasingly shown interest and commitment to integrating the new development agenda into their sustainability strategies. According to a PwC report, $71 \%$ of businesses said that they were planning to engage with the SDGs in $2015 .{ }^{15}$ While sustainability was not considered core for multinational companies in the past, that view has been changing rapidly because global forces such as environmental impacts, globalization, urbanization, competition for raw materials, and technological disruptions are fast-paced and challenging business models in many sectors. Furthermore, consumers and investors are increasingly interested in understanding how companies are contributing to society and are requiring transparency of sustainability matrices. ${ }^{16}$

The mining sector is no exception. While companies have long been concerned with obtaining and retaining their social license to operate, developing interventions that support communities affected by their operations has tended to be the responsibility of the headquarters-based corporate social responsibility (CSR) department. Moreover, these interventions have often not been viewed as part of the core business and have been developed without taking sustainability into consideration. With increasing community opposition to the sector as a whole and more information available about the cost of social conflict, ${ }^{17}$ mining companies are seeking new business models that help to address the impacts of the sector on those most affected by operations.

The strength of the SDG framework is that it provides an opportunity for mining companies to align their strategy, incentive mechanisms and interventions to national and sub-national priorities. CCSI and its partners have mapped out examples of how the mining sector can support the SDGs ${ }^{18}$ 


\section{Figure 4: Interaction of strategies}

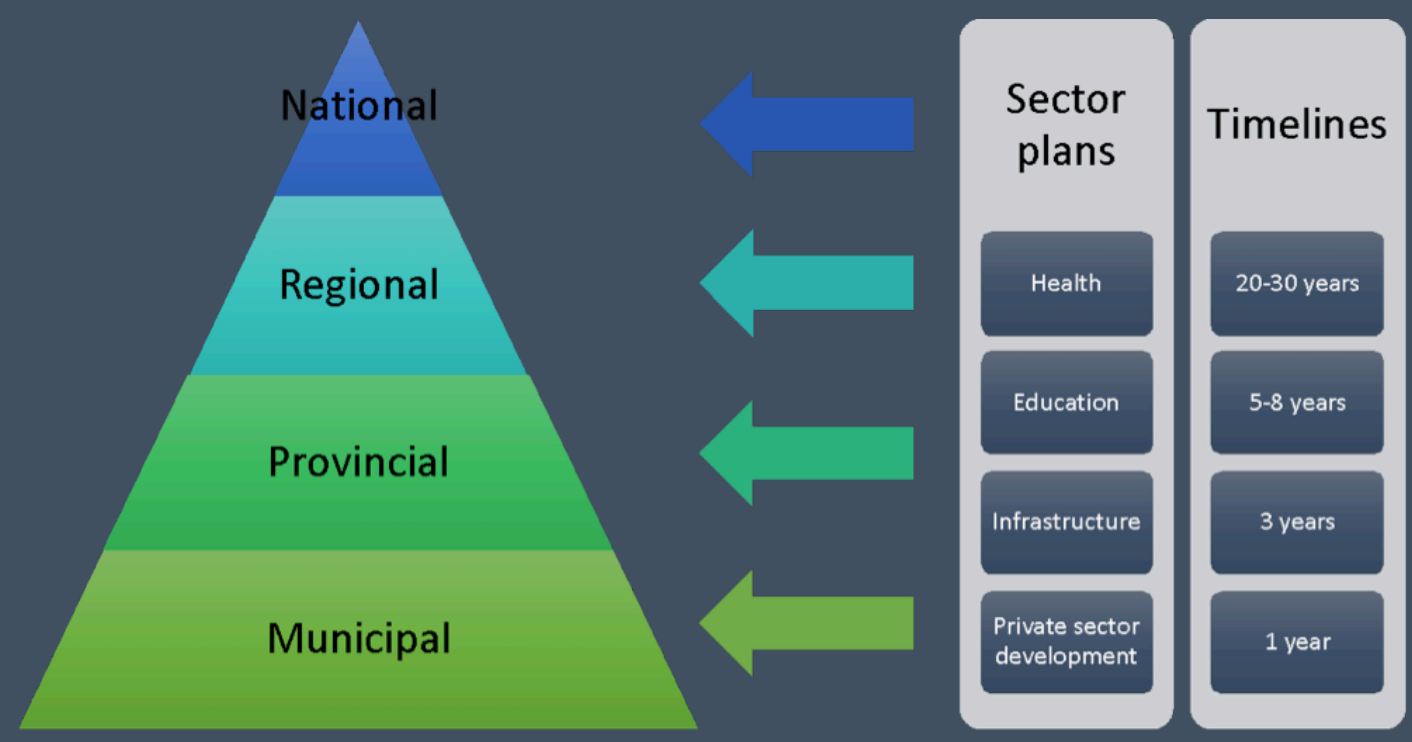

Private sector and donors to align interventions to above strategies according to where, in which areas and how long they operate.

\section{Interaction and alignment of development strategies}

As mentioned above, one of the main purposes of development strategies is to provide guidance and coherence among and within government institutions. At the horizontal level, ministries and institutions responsible for different sectors should avoid duplicating interventions. At the vertical level, the national and sub-national should avoid duplicating interventions. As such, strategies by these various actors within the government should align and inform each other. While the exact interaction will be dependent on the country's institutional structure and level of decentralization, Figure 4 illustrates the various components that need to be considered. The triangle on the left-hand side of the graphic shows the vertical component. The national level strategies should inform the sub-national level strategies and policies. Sectorspecific plans, such as health, education, infrastructure, or private sector development strategies, should in turn contribute to the broader visions at the national and subnational levels. Other stakeholders, such as donors and the private sector, should align their interventions to the vertical and horizontal strategies of the government.
At each level, the strategies will have to be broken down in order to implement and operationalize them. The longterm development strategy should have a timeline of 20-30 years and outline the vision of where the country/region/ province or municipality wants to be in the future. The vision should contain measurable objectives and targets, but by the very nature of the timeline, it is not going to be detailed in terms of policy interventions to achieve these. Policy interventions should be contained in 5-8 year plans that oftentimes coincide with election cycles. In these plans, the governing party outlines its priorities while in office, which should help achieve the targets set out in the long-term development strategy.

To implement the policies, financial resources are needed. This is where more detailed annual and 3-year programs need to be developed that are backed by resources. The budget allocation is ultimately the best indicator of what is prioritized. Medium-term expenditure frameworks (MTEF) are a useful tool to bridge annual financial resource constraints with priorities that require longer-term budgeting. For example, large-scale infrastructure projects may bridge annual budget cycles. The responsible entity therefore makes a two to three-year prediction of the budget, which is then linked to specific targets. In this way, after the first year, there is an evaluation which determines adjustments for the following year's budget. ${ }^{5}$ 
To track the budget priorities of the Government, it is best practice to make expenditures public. One positive example of financial tracking comes from Mexico City, which is developing a platform that will allow users online access to monitor the progress of development indicators against objectives, as well as track public spending.

\section{Box 2: Mexico City’s budget monitoring system}

The "Monitoreo CDMX" portal was launched in April 2016 under the leadership of the General Coordinator for Administrative Modernization of Mexico City. It allows users to carry out queries on the progress of the objectives contained in the city's development plan by program and/or development dimension. ${ }^{6}$ In February 2018, the portal incorporated SDG-related indicators, and as of 2019 it also tracks the amount the city has spent on each program.

This will enable users to assess spending priorities in relation to progress and objectives. Apart from helping users assess the local government's performance, this tool will help the city implement more efficient and effective financial planning in the short- and medium-term. ${ }^{7}$

Companies and donors play a key role in many jurisdictions bysupporting the various levels of government with financial resources, technical support, and the implementation of interventions. These support mechanisms should be closely aligned with the government strategies and budgets so as not to duplicate efforts. Transparency around where financial resources are provided and what projects are supported is key to avoid duplication of efforts and to reduce opportunities for corruption. The Timor-Leste Aid Transparency Portal ${ }^{8}$ is an example of a publicly accessible dashboard where stakeholders can easily access information about what sectors donors are contributing to, how much they are financing, and in which municipalities projects are being financed. The \#Business4SDGs Dashboard (see section 7.5) is another example of a dashboard where private sector companies publish the projects that they are supporting.

\section{Process to develop a development strategy}

The development planning process should be divided into three stages: (1) the elaboration of a diagnosis of the territory, considering its resources and challenges; (2) the development of specific goals and targets based on the identified vocation of the territory; and (3) the development of a monitoring and evaluation system that allows stakeholders to oversee progress and implement changes as necessary. The following section will provide more detail on each step, as well as relevant case studies that help exemplify the content.

\subsection{Diagnosis of the territory: An inclusive assessment}

To ensure that the development strategy has ownership and receives support from all stakeholders in the region (including political opposition parties), it is crucial to have an inclusive process from the start. This requires discussions about the diagnosis of the territory, which should be the baseline for the development strategy. As such, the diagnosis should be composed of (1) a thorough review of existing strategies and policies; (2) a baseline and benchmark analysis; and (3) public consultations.

Planning processes are not organized in a void, but rather are exercises that emerge from the interest of a group of actors in establishing a set of goals and targets that build upon the progress that has been made at that point in history. As a result, there are often multiple strategies and policies that have already been elaborated in the past. Rather than starting from scratch, it is important to build on good policies and initiatives. It is therefore crucial to revisit existing plans and policies, and assess what has or has not worked and why. The review should encompass all levels of government and also include activities by non-governmental organizations (NGOs) or private sector actors to render a full picture of what has and is currently being supported in a territory.

A data-based baseline and benchmark analysis are key to understanding the needs and how the territory performs in relation to comparable jurisdictions. Oftentimes data is not easily accessible at the sub-national level and developing a survey for the baseline assessment may be too costly and time consuming. If so, discussions with the national statistics office regarding disaggregation of survey and census data may be necessary. Data can also be obtained from previous studies undertaken in the region. Large scale mining projects are required to conduct social and environmental impact assessments for which large datasets need to be collected and analyzed. Conversations with 


\section{Box 3: Public consultation in Colombia}

Figure 5: Linkages between the Medellin Development Plan (PDM) and the SDGs

Colombia is one of the countries in Latin America that has invested large amounts of political and economic resources for the implementation of the 2030 agenda at the national and sub-national levels. In the elaboration of its development plan, the City of Medellin matched 169 indicators with the SDGs (Figure 5). After the initial assessment, the results were submitted to 9 thematic consultation groups with the relevant stakeholders per sector (education, health, economic development, security, environment, mobility, population, cooperation, and land development) for evaluation. The selected indicators were submitted online in order to be assessed by Medellin's citizens. ${ }^{19}$ The platform allows users to make comments on each objective and prioritize them.

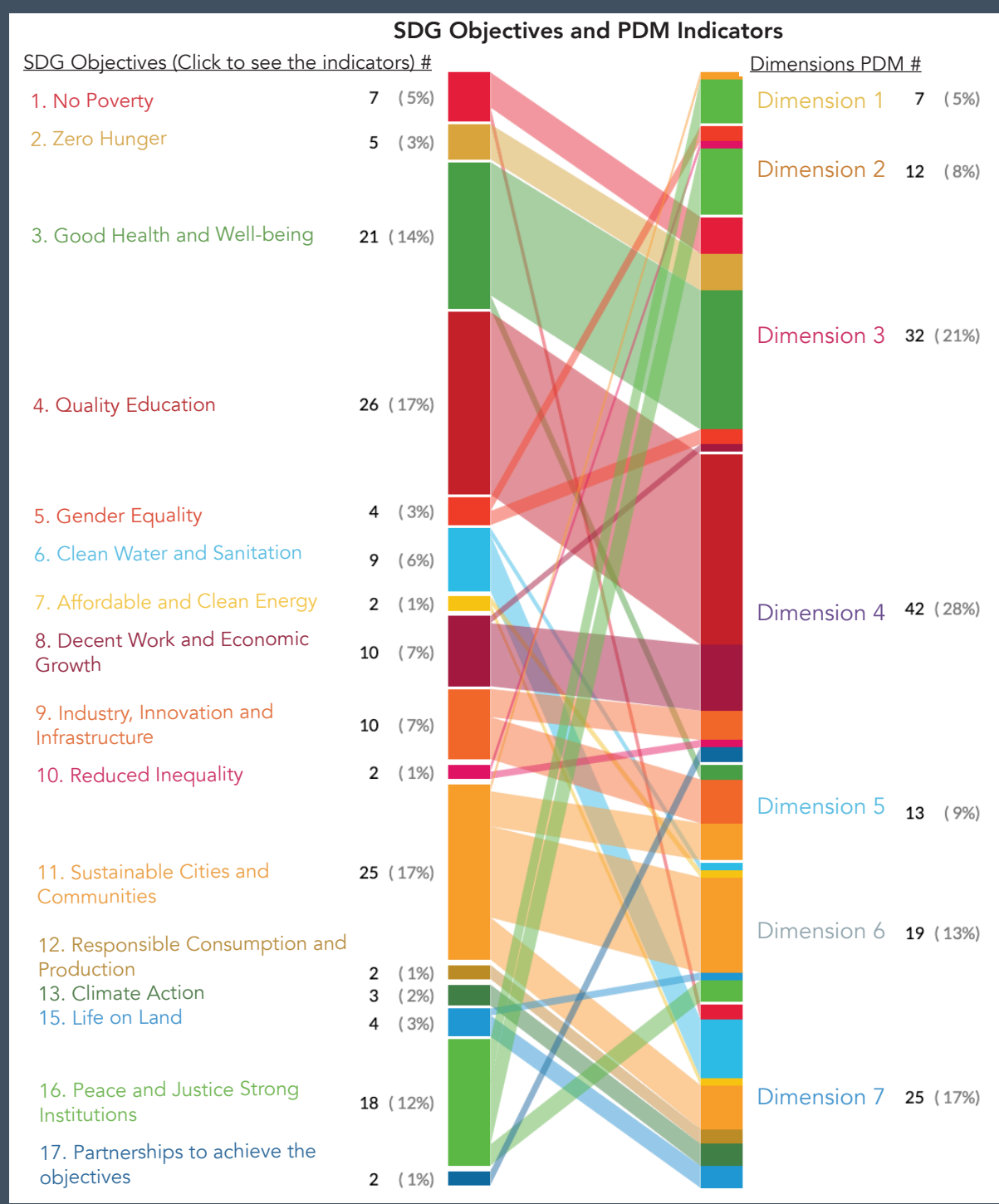

Source: Alcaldia de Medellin, "Análisis de la correspondencia entre el Plan de Desarrollo y los Objetivos de Desarrollo Sostenible," (2017). ${ }^{20}$ 
the local authorities and service providers may provide additional information. Highlighting data gaps during the assessment is critical - particularly if these data are necessary to define and measure specific targets in the development strategy.

Once the baseline is completed, it is important to compare the data with that of the similar or neighboring jurisdiction, as well as with the national and international indicators. This will help determine where the territory lags behind and will also signal where potential 'quick wins' could materialize by learning from and replicating interventions in neighboring territories. The SDG framework provides a unique opportunity for comparability.

Apart from creating ownership, consultations with the various stakeholders living and working in the territory provides an insight that data does not necessarily convey. A good example of an inclusive consultation process comes from the City of Medellin (Box 3). It has implemented a series of expert and public consultations where civil society was involved in the selection of goals and indicators that they felt were more representative and meaningful for their context.

\subsection{Defining objectives, goals and targets}

Once the participatory diagnosis has been completed, the next step is to determine the priorities of the development strategy, and how these can be measured.

\section{Determining priorities}

The guiding principles that should be followed when defining goals and targets in a development strategy include: (1) The selection of priorities should be based on the gaps of the territory (an effective plan will be based on hard data to support evidence-based decisionmaking); (2) the objectives should be within the mandate of the authority responsible for implementation; and (3) the selected objectives need to be in accordance with the financial and technical capacity of the involved stakeholders. ${ }^{9}$

To implement these guiding principles and ensure ownership, the following three planning tools should be used to determine the objectives, priorities and targets of the development strategy:

1. Multi-stakeholder planning processes: Like the diagnosis stage, strategic partnerships are critical to determine objectives, priorities and targets. They not only create ownership and co-responsibility but also promote capacity building and foster further cooperation. ${ }^{10}$

2. Backcasting for goal-based planning: Unlike forecasting, which estimates outcomes based on current trends, backcasting begins with a projection of successful outcomes and works backwards to understand what is needed to realize the outcomes. ${ }^{11}$ This methodology is useful to plan for the future, basing outcomes on present scenarios and facilitating the establishment of short- and medium-term goals.

3. Financing analysis and investment strategy: This consists in aligning the source of funding with each priority and its related activities. While it will not be possible to do detailed budgeting over a twenty-year period, identifying sources and gaps will help determine whether objectives are achievable and if they can contribute to the long-term financial sustainability. ${ }^{12}$

A good example of a multi-stakeholder planning process around a mining project comes from Huasco Province in Chile where CCSI and Dinamica Plataforma supported NuevaUnion in the elaboration of a development roadmap for the region (Box 4).

\section{Data requirements to measure priorities}

Once the priorities have been identified, it is crucial to determine the indicators and data that will be used to assess progress. The data selection process should take the following considerations into account: ${ }^{13}$

- Collect comparable data where possible: As a starting point, the SDGs provide indicators that can measure development outcomes. Using these indicators enables comparison opportunities. Additionally, it is worth reviewing the indicators selected by the national and regional governments in order to secure policy coherence and facilitate data sharing.

- Avoid exclusion of marginalized populations: Aggregated data tends to overlook marginalized groups. This results from only recording averages, or even complete under-recording due to the informality in which communities live in. It is important to collect disaggregated data that helps identify the most vulnerable members of society to be able to tailor social and economic policies to help these groups have equal access to opportunities. 


\section{Box 4: Roadmap for the sustainable development of Huasco Province}

The NuevaUnion project is a prospective copper-gold mine located in Huasco Province in Northern Chile. The project foresees infrastructure developments to produce and export the ore throughout the four Communes that make up the Province. To receive the backing and support of local stakeholders, the project proponents engaged in an exemplary bottom-up community participation process even prior to obtaining the necessary approvals from the authorities to develop the mine. The value proposition of the project seeks to move towards a scenario of co-existence with all the interests present in the territory.

Among the main challenges facing the Province, include social, environmental, and economic gaps when compared to the Region and the Country. Furthermore, there is a strong competition for limited resources among the main economic sectors, namely mining, agriculture, and increasingly, tourism. Climate uncertainty with increasing droughts followed by downpours that have caused flash floods in the past put further pressure on its population. Social tension in the Province around the management of and competition for natural resources have seen two large-scale investments fail in the past.

Within this context, NuevaUnión embarked to develop the "Roadmap for the Sustainable Development of Huasco Province" with the aim to outline a common vision of where the inhabitants would like to see themselves in the years to come. To achieve this, an unprecedented social dialogue process was carried out over 16 months. The methodology, designed during the initial development of the initiative, considered an integrated and interdisciplinary perspective, adopting the Sustainable Development Goals (SDGs) of the United Nations, which were necessary to identify the path to long-term sustainable development and to construct a common vision for the future. More than 120 participants from various stakeholder groups were convened including impacted communities, civil society, indigenous groups, government, and academia.

During the first stakeholder meetings, the results of a comprehensive territorial analysis were presented. This included a statistical review of available indicators at the Commune and Province level, that were compared to the Region and the Country to assess development gaps. The SDGs were used as a guiding framework for this exercise. Furthermore, the existing Regional, Provincial and Communal government plans were reviewed and summarized in the initial meetings to ensure that the roadmap would build on and complement existing efforts throughout the Province.

Building on the baseline analysis, the following workshops were designed in a way for participants to contribute to a common vision for the Province and to identify strategic interventions that would help achieve the vision. Through a participatory process, the roadmap was broken down into five key pillars. Each pillar includes the objectives; challenges to achieve that objective; whether it is high, medium or low priority; whether it can be achieved in the short-, medium- or long-term; and whether the interventions need to occur at the Communal, Provincial and/or Regional level to achieve the objective.

The roadmap consists of five pillars for territorial development that converge in a common vision:

1. Our Huasco, which recognizes the incalculable value of heritage and the cultural roots of the territory.

2. Human Huasco, which puts at the center the need for inclusive and equitable development.

3. Prosperous Huasco, which promotes economic growth and productivity.

4. Integrated Huasco, which highlights the importance of multi-stakeholder partnerships that promote participation of its citizens and collaboration between the public and private sectors.

5. Natural Huasco, where the challenges of ecological sustainability and climate change are addressed.

Using the SDGs as a guiding principle throughout the process helped to get the various stakeholders to agree on development objectives. Furthermore, the need for comparable indicators and data at the local level to track progress was repeatedly identified as one of the main challenges to work towards the achievement of the objectives and long-term vision.

One preliminary lesson learned from this process was that the conversation shifted from the more traditional risk management perspective to a more holistic understanding of the challenges and expectations of the community. Conversations became less defensive and it helped to set a good starting point for a successful collaboration to see the community prosper.

Source: Provincia del Huasco (2019) Huasco: Hoje de Ruta para el Desarrollo Sustentable de la Provincia del Huasco. Available at: http://ccsi.columbia.edu/files/2018/03/Provincia-del-Huasco-Sustentable.pdf 
- Strengthen capacity for self-producing data: With new technologies, self-producing data collection systems can be developed at a lower cost than in the past. The real-time nature of such data systems is an additional benefit allowing policymakers to react quickly.

- Maintain data independence and reliability: Information has to be produced and managed independently to avoid politicizing fact-based decision making.
- Align data to public programs and budget administration: One of the primary objectives of this exercise is to help planning and implementing agencies to use the data to improve their programming and budgeting. As such, these actors should be closely consulted.

The table below summarizes a step-by-step guide of how to determine a useful data portfolio to measure development progress.

Table 1: Deciding on the right data and monitoring systems

\section{Step Description}

Assemble highest-priority decision needs. Use the SDGs as a foundation. Utilize consultative dialogues with experts, national and local government officials, private sector representatives, and civil society.

Data inventory that can be counted on from existing sources. Utilize desk research and consultations with local and international data experts.

Catalog data technologies in use elsewhere for similar decision needs. For the decisions that are the most important, what data sources are in use worldwide, and which seem most effective? Utilize consultations with international development and data experts.

For the most important decision needs, evaluate the fitness of relevant data sources identified in steps 2 and 3. To the extent possible, use common benchmarks such as cost, accuracy, timeliness, spatial precision, authority, and update frequency. If quantitative estimates are not possible, use expert judgment to assign an estimate or a qualitative score. Bring together participants in step 1 with local and international data experts.

Using the results from step 4, create first-order matches between available data sources and decision needs. Which data sources are most promising for meeting decision needs? Use the same participants as in step 4.

Begin an iterative process to move from single-data-source evaluations to portfolio-based evaluations. For decision needs where data availability is heavily cost-constrained, explore options for bringing costs down through blended approaches. Typically, such options will emerge when there is a costly approach that is inadequate because of spatial coverage or update frequency; and a less expensive approach with good spatial coverage and update frequency but lower on other criteria, such as accuracy or authority. Blending satellite and ground station air pollution data is an example.

If the data options are constrained by some other parameter, e.g. accuracy, explore options for mounting a selective new measurement campaign optimized to boost that parameter in the overall portfolio. Such options are likely to emerge when the value of information is very high (because of its impact on priority decisions) but none of the available data sources generate adequate information, even in combination.

Test the recommendations that emerge from step 6 by generating sample data products and reviewing their value with the stakeholders from step 1.

Where specific approaches emerge that appear to provide high value relative to cost, begin producing relevant data products. It is important to generate the first products in an open manner with opportunities for review by experts and users, and with appropriate validation exercises, in order to achieve quality and trust. 


\subsection{Setting up a monitoring and evaluation system}

The final component to implement a successful development strategy is a transparent monitoring and evaluation system that helps the relevant stakeholders to track progress. Benefits of such a system include improved decision-making for policymakers in designing programs and interventions, assessing what interventions have and have not worked, and increasing accountability.

The following guiding principles help set up a robust monitoring and evaluation system:

- Political will: The engagement of local governments' leadership is highly desirable since it will guarantee that the system is supported and used.

- Central agency: Although partnerships are essential, it isimportanttohavealeadingagencyororganizationthat administers the information and maintains the system.

- External evaluation: The information needs to be verified by an independent third party, and it should be open for the population to check and follow up.

Apart from government access, other stakeholders and the general public should also be able to use such a platform. To make it useful, the platform should be easy to navigate and visualize results.

The underlying principle is not to 'reinvent the wheel' but to adapt and strengthen local reporting mechanisms, to choose an efficient monitoring platform, and to benefit from innovations that promote accountability and transparency. Depending on how different priorities are set up by local stakeholders, sources of information and/ or data collection modes might include local committees or dedicated extension agents; facilities such as schools, clinics and/or health posts, and transportation hubs; monitoring sensors for water and/or air quality installed at key locations, among others.

In a mining context, the Minera Los Pelambres project (Box 5 ) is a good case study where an SDG-based monitoring system has been developed.

In the annex of this report, several additional planning and monitoring tools are outlined to show technological features that can be integrated such as real-time data monitoring, benchmarking options to peer jurisdictions, spatial assessment overlaying mining-specific data, population perception integration, and private sector alignment examples.

\section{Box 5: SDG monitoring system in Choapa Province}

Minera Los Pelambres (MLP) is a copper project owned by AMSA, one of the largest copper producers in the world. The operation is located in Northern Chile in the Choapa Province. MLP's operations cross the province with the mine being located in the mountains and the export point at sea. To support the development of the Province, MLP has launched several initiatives such as the Foundation "Minera Los Pelambres" and the community investment initiative "Somos Choapa".

Recognizing the importance and potential of the SDGs for the mining sector, AMSA seeks to concretize its alignment with the Agenda 2030 to improve the effectiveness of their interventions. In this context, Columbia University's Columbia Center on Sustainable Investment (CCSI) and the Center for International Earth Science Information Network (CIESIN), together with its local partner Dinámica Plataforma, were asked to perform an SDG baseline assessment of the Province. Existing data and information were used to develop an SDG-based data tool that compares the SDG performance of the Communes and Province with that of the regional and national levels. This helps to visualize the challenges and advances of the territory, thereby providing useful inputs into the decision-making process where interventions should be prioritized. Furthermore, by reviewing how the indicators develop over time, the efficiency of interventions can be monitored.

Following the completion of the territorial baseline, MLP's development interventions through the foundation, the community investment initiative or other programs by the company are also being mapped against the SDGs and will be integrated in an evaluation system. This will allow MLP to measure the contribution of the interventions to the SDGs, thereby providing a feedback loop.

Source: Los Pelambres, AMSA 


\section{Figure 6: SDG Dashboard of Choapa Province}

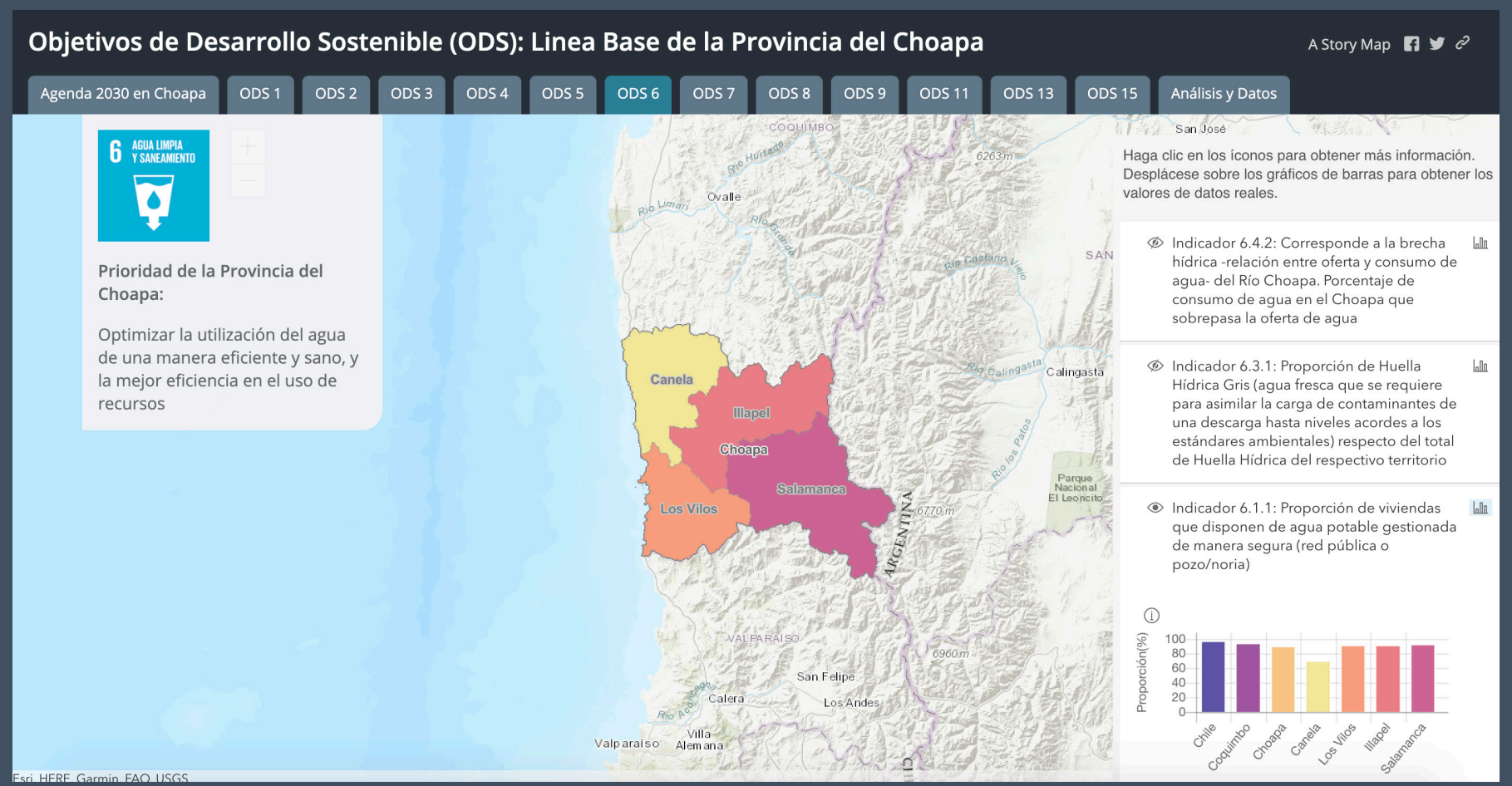

Source: Los Pelambres, AMSA

\section{Conclusion}

Strategic development planning has long been used by private and public sectors to guide actions that will lead to a determined goal in the medium- to long-term. The SDG framework has helped to create a common language of what development means, what the global objectives are by 2030, and how progress can be measured. With the world entering an era in which data is generated and used at an unprecedented scale, data and ICT systems should be used to better inform policy decision making and help evaluate progress to hold stakeholders accountable to their promises and performances.
This report has outlined how two mining projects in Chile are using planning and monitoring tools to advance development objectives beyond the mining-impacted areas. Several additional examples are showcased in the annex on how governments, companies and civil society are using improved data accessibility and technological advances to help achieve and monitor their objectives. The figure below summarizes the characteristics of the different tools showing the range of possibilities, including real-time data indicators, participatory processes, datasets from various sources, map-based systems, peer-to-peer comparisons, extractive industry specific data, whether there is a focus on private sector inclusion, and if the tool is hosted by a third party rather than the Government. 


\section{Figure 7: Overview of case studies}

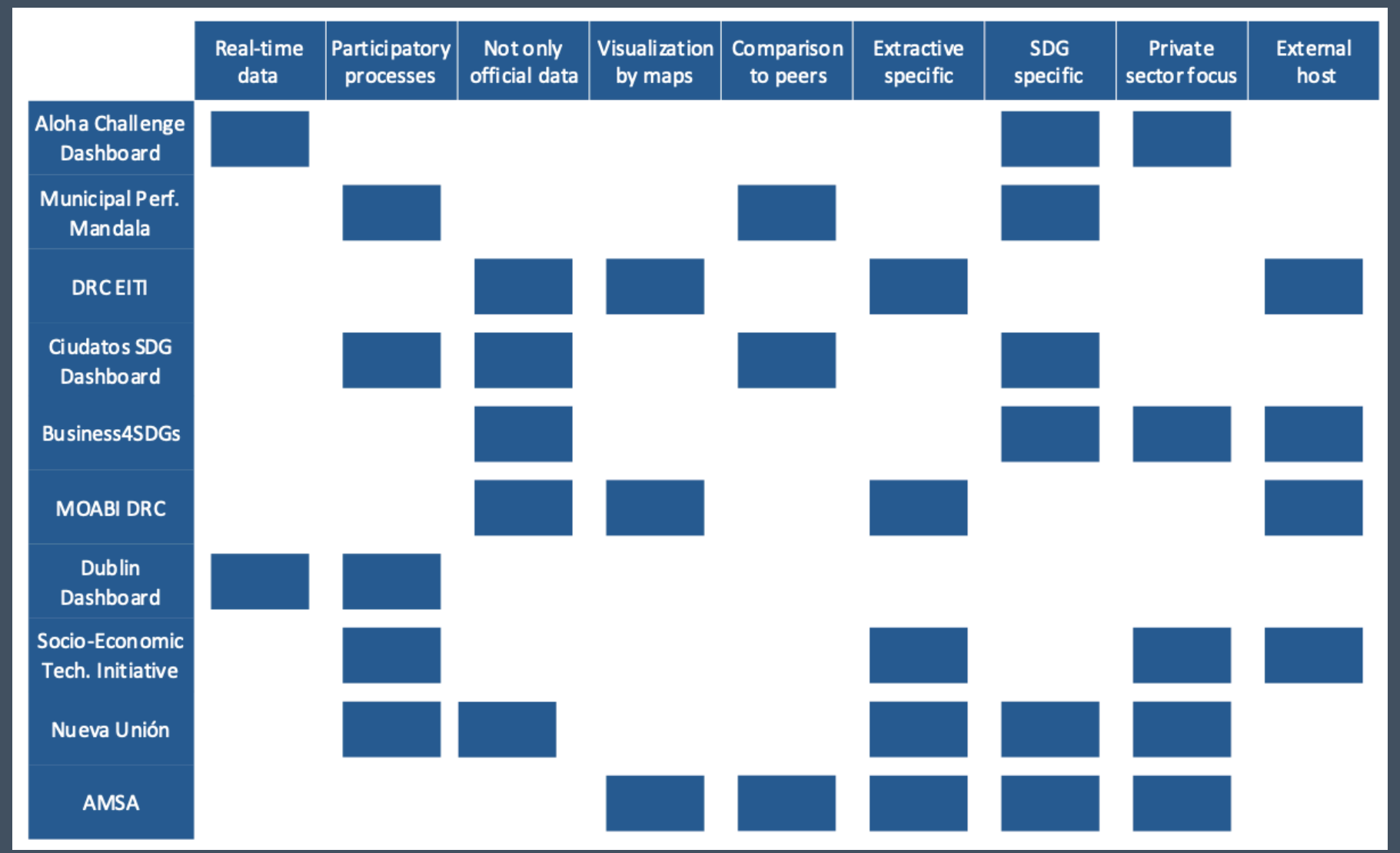

Source: Authors

The choice of characteristics that a development planning and monitoring tool should have, will be highly context specific. This will depend on the priorities by the stakeholders, the availability of data, and the availability of resources. Defining these will have to be part of a consultative process.

It is important to note that these technological platforms cannot replace the participatory and consensus-based nature needed to implement a long-term development strategy successfully. Without participation and buy-in from the impacted population, the best data platforms are going to fail. This is because objectives may change based on political cycles, or because parts of the population will not identify with the objectives nor trust the data and results. It is therefore crucial to involve a wide range of actors from the outset when devising a long-term development strategy, defining the objectives and targets, choosing indicators to measure progress, and setting up a platform to help decision making and monitoring progress.
The SDG framework and the case studies outlined in this report can help guide this process.

As the mining sector is increasingly automating and digitalizing operations to increase efficiencies and reduce costs, there is also a unique opportunity to support local stakeholders in reaping the benefits that the data revolution has to offer. Not only will this help improve development outcomes in mining regions, but may also go a long way to help secure or retain the social license to operate. 


\section{Annex: Case studies of tools and resources}

To showcase how data-based systems can support policy-making, help monitor developments on the ground, and inform the public, this annex features 8 example tools. This is non-exclusive and merely aims to provide an overview of some of the features that stakeholders may want to consider when devising a planning and monitoring tool in mining-impacted jurisdictions. The case studies include features such as real-time data monitoring, benchmarking options to peer jurisdictions, spatial assessment overlaying mining-specific data, population perception integration, and private sector alignment examples. Each case study outlines the objective of the tool, the process followed to develop the tool, and the impact that the tool has had.

\section{Aloha Challenge Dashboard: Public and private sector alignment}

\section{Objective}

The Aloha Challenge Dashboard is an online platform designed for decision-makers and the public to track Hawaii's annual progress on achieving the sustainability goals in clean energy, local food production, natural resource management, solid waste reduction, smart and sustainable communities, green workforce, and education. The Dashboard currently features indicators at the state and county levels. ${ }^{21}$ Private sector efforts are also included. Progress in energy efficiency is tracked for those companies that are a part of the Sustainability Business Forum (SBF). The figure below shows the improvements made by Hawaiian Airlines.

Figure 8: Green Your Business Initiative renewable energy target tracker

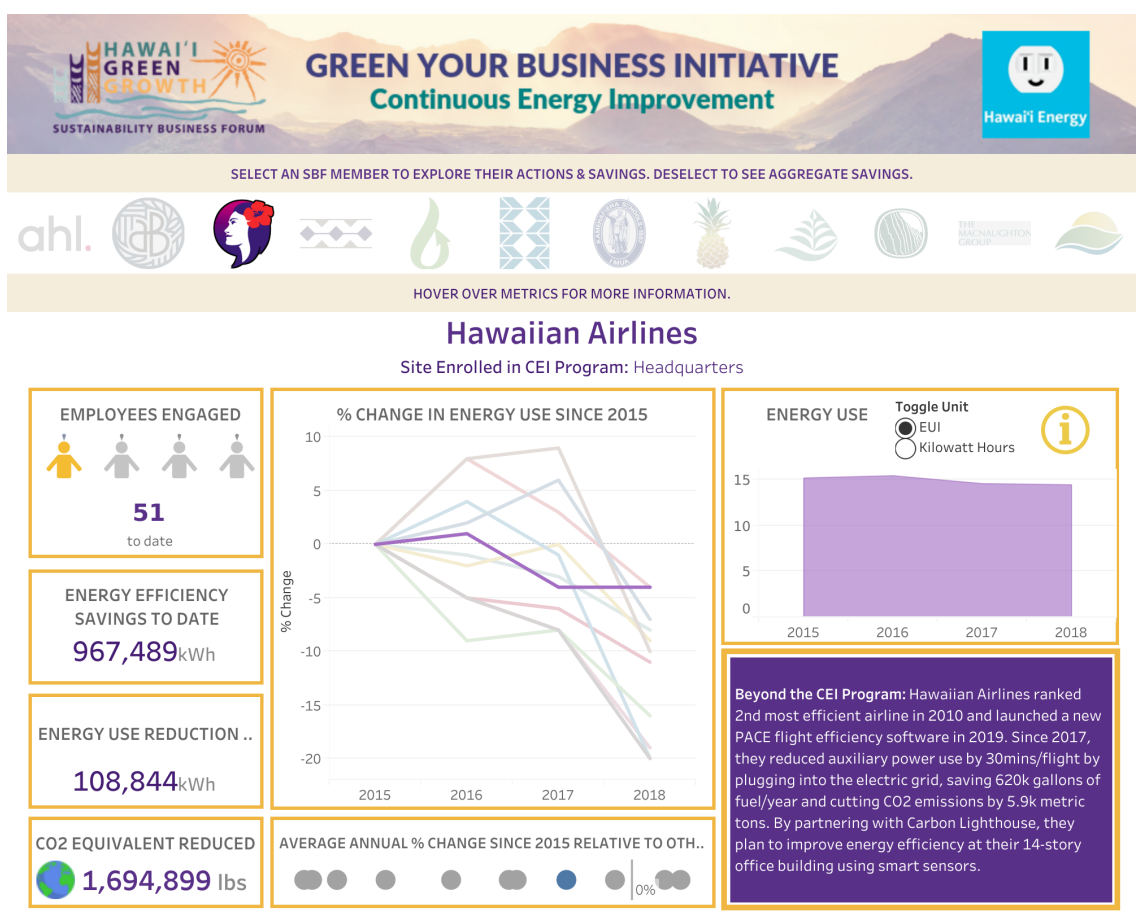

Source: Aloha Challenge Dashboard 


\section{Process}

The Aloha Challenge Dashboard is a public-private stakeholder initiative involving multiple state departments, all four Hawaiian counties, the Office of Hawaiian Affairs, the University of Hawai'i System, and Hawai'i Green Growth (HGG). The team is responsible for ensuring data compatibility and tracking progress against Hawai'i sustainability goals. The Dashboard is hosted by the State of Hawai'i Office of Information Management and Technology, which also provides ongoing technical support.

The HGG, one of the key stakeholders in the group, is a multi-sector voluntary partnership of more than 60 leaders from government, non-governmental and cultural organizations, business, academia, and philanthropy. The strength of the HGG lies in building a statewide network that fosters change, action, and innovation. Under the HGG, leaders develop shared priorities for action, support innovative funding mechanisms and legislation, develop shared indicators to track progress, and engage with international partners to help achieve the Aloha+ Challenge targets.

To develop the targets, indicators, and the Dashboard, consultations took place over several years with support from stakeholders of a variety of backgrounds. The design of the Dashboard was based on the idea to provide simple, easy-to-understand figures and graphs to track the progress of the Aloha+ targets at a state and county level. The first version of the Dashboard was launched in 2015 as an online open-data platform. It has been updated and improved since. ${ }^{22}$

\section{Impacts}

The implementation of the Aloha+ Challenge and its Dashboard has been largely impactful by generating greater engagement within the private sector to further pursue the established development goals. An example has been the creation of the Sustainability Business Forum (SBF), a group of Hawai'i business executives who are committed to triple bottom line outcomes, building community resilience, and advancing the Aloha+ Challenge. ${ }^{23}$ The members of the SBF represent over 21,000 employees, $\$ 8.5$ billion in revenue, and \$95 million in annual philanthropic donations. Two initiatives of the SBF are closely linked to the Aloha+ Challenge Dashboard: The 'Green Your Business Initiative' which asks SBF members to share their energy efficiency data, which is then tracked on the Aloha+ Challenge Dashboard; and the 'Sustainable Tourism Initiative,' where the SBF has provided key inputs into the sustainable tourism metrics used on the Dashboard. ${ }^{24}$

\section{Municipal Performance Mandala: Comparing performance across municipalities with similar characteristics}

\section{Objective}

The National Confederation of Municipalities of Brazil (CNM) developed the "Municipal Performance Mandala" (Mandala) tool in 2017 to assess the progress of the Municipalities against the targets established by the National Government in its Development Plan. Through Mandala, local governments and civil society can monitor the progress of 28 indicators along four dimensions of sustainability -environment, social, economic, and governance.

For users to be able to compare municipalities with their respective peers, several characteristics such as population and poverty indicators are used to create 'peer groups'. The software then calculates the position of the municipality in relation to the other municipalities in its group. This avoids comparing, for example, rural and urban municipalities with different economic characteristics. ${ }^{25}$ 


\section{Process}

The United Nations Development Program (UNDP) supported the SDG localization in Brazilian municipalities by developing a "Guide to the Integration of Sustainable Development Goals in Brazilian Municipalities." This guide aimed to assist municipal managers in integrating the SDGs into Brazilian Municipal Plans for the 2018-2021 period by outlining the inter-linkages between the goals and their interconnectivity to the planning of municipal management. The project supported the development of the "Municipal Performance Mandala for Local Indicators." 26 Mandala was built based on the indicators and criteria set out by technical experts and employees of the National Confederation of Municipalities (CNM). The process was publicized in a subsequent outreach campaign.

In Figure 9 the red area represents an area where the value of the selected indicator is considerably lower than the mean value of the same indicator among the municipalities in the peer group. The yellow circle represents an area where the value is somewhat below the mean, and the green circle includes indicators where the municipality is performing better than the mean.

Figure 9: Sample visualization of the Mandala Dashboard with the selected indicators

\section{Example of São Paulo}

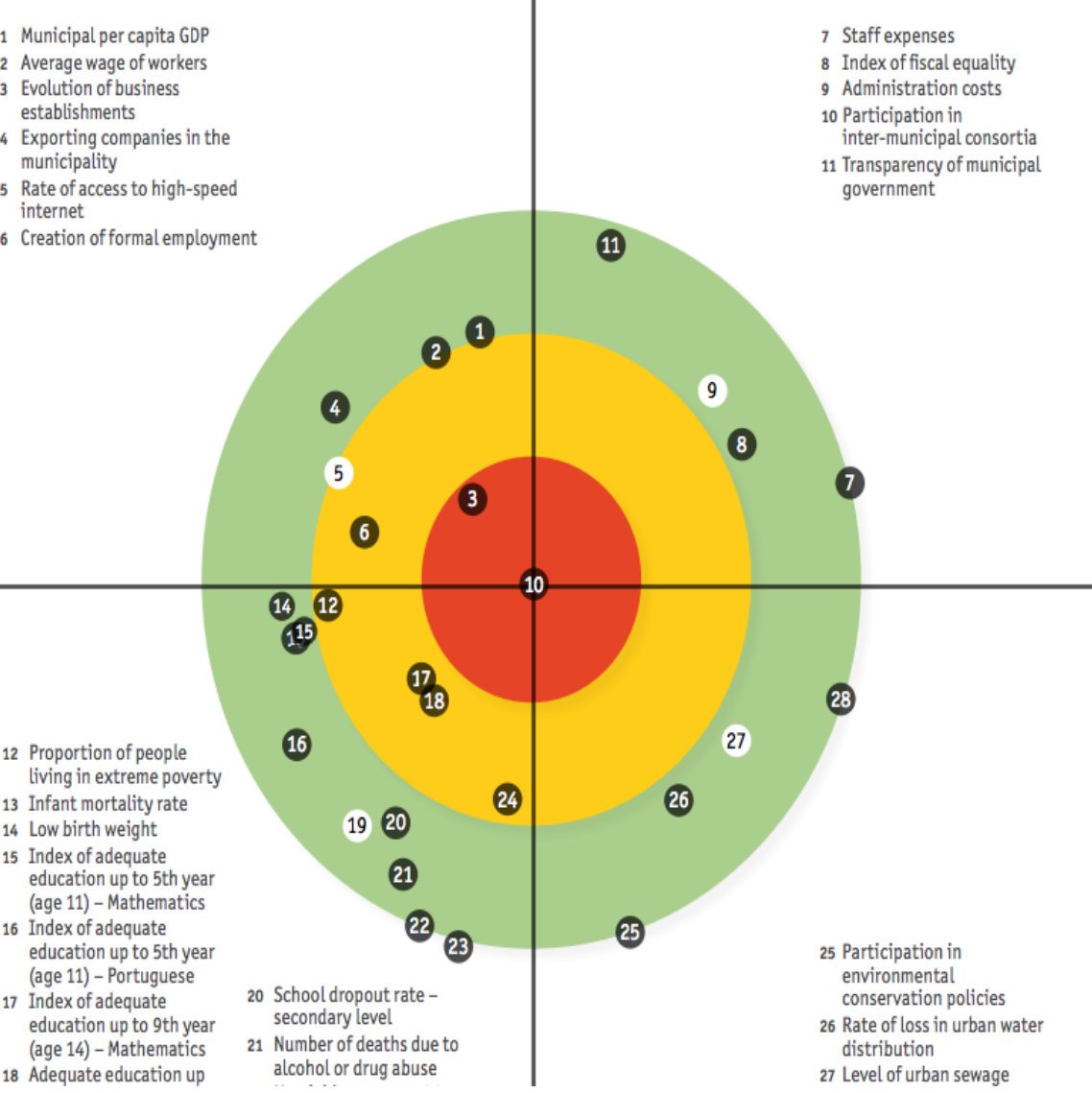

Source: UCLG, "Monitoring the global agenda in municipalities: the Mandala tool," (2018), p. 5 
Figure 10 shows a comparison of the environmental performance of Sao Paulo and Rio de Janeiro - two cities that are in the same peer group. Rio de Janeiro has a worse Sewage Collection Index than the mean (represented by the letter $\mathrm{C}$ in the figure).

Figure 10: Comparison of Sao Paulo with Rio de Janeiro environmental performance

\section{Sao Paulo 2019}

INSTITUCIONAL
ECONÔMICO
SOCIAL
A Participação em políticas de Conservação
Ambiental
B índice de perdas na distribuição de água
urbana
C índice de Coleta de esgoto - urbano
D Taxa de cobertura de coleta de resíduos
domiciliares urbanos

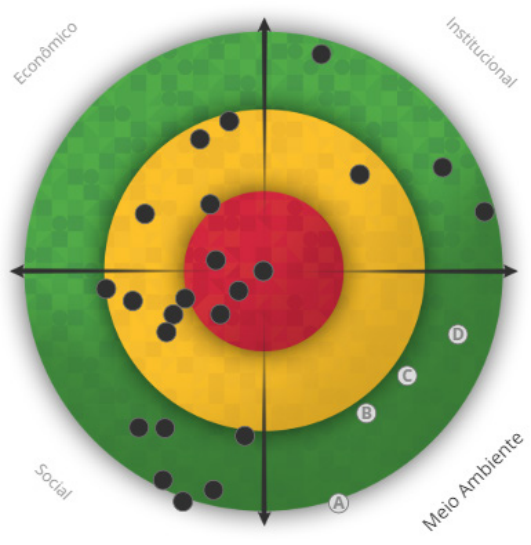

\section{Rio de Janeiro 2019}

\begin{tabular}{l} 
- INSTITUCIONAL \\
- ECONÔMICO \\
- SOCIAL \\
- MEIOAMBIENTE \\
\hline
\end{tabular}

\footnotetext{
A Participação em políticas de Conservação Ambiental

B índice de perdas na distribuição de água urbana

C Índice de Coleta de esgoto - urbano

D Taxa de cobertura de coleta de resíduos domiciliares urbanos
}

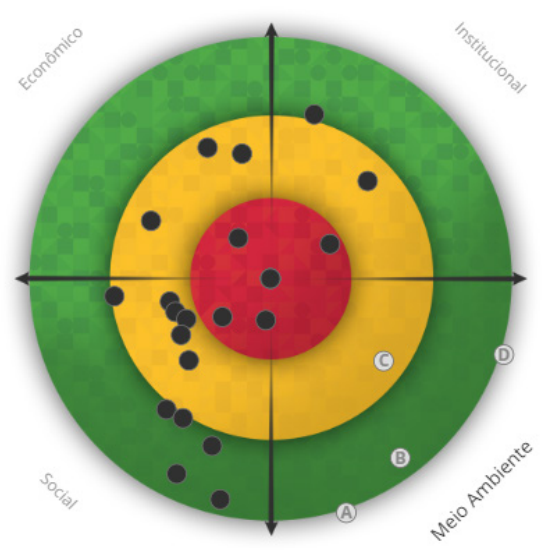

Source: Mandala website

The Mandala tool has a feedback mechanism whereby municipalities, associations, and other users are asked to provide suggestions about how to improve the tool. The tool is overseen by a group of experts who monitor its implementation and propose new applications. ${ }^{27}$

\section{Impacts}

The tool has helped municipalities integrate the SDGs in their planning processes. Partners like the UNDP and private sector actors like Petrobras have also used the tool to propose new projects with the aim to improve indicators measured by Mandala. ${ }^{28}$ 


\section{Democratic Republic of Congo EITI: Spatial assessment tool focused on mining}

\section{Objective}

The spatial data catalog for the Democratic Republic of Congo aims to help mainstream transparency of government systems and improve stakeholder access to financial information from the Extractive Industry Transparency Initiative (EITI) reports. It seeks to achieve this goal by bringing together data sets from various sources. The tool includes data related to natural resources, biodiversity, socio-economic and development indicators, and EITI reports. The tool processes the data in a way that is interpretable and can be linked back to the location of the mine sites by showing it on a map. ${ }^{29}$

This helps with inter-ministerial coordination on issues such as strategic land-use planning, license overlaps, and the identification of social and environmental risks. It also allows for the public to monitor the mining sector. The evolution of licenses and indicators can be traced with a time-slider function. This functionality was developed at the specific request of the DRC stakeholders and it was applied to visualize the extent and validity of mining licenses over time. A heat map functionality was developed to visualize the extractive industries' payment and production data across different regions. The figure below overlays poverty with the EITI payment data. ${ }^{30} \mathrm{It}$ suggests that higher payments by the mining sector in the East of the country do not necessarily coincide with lower poverty levels in the region.

Figure 11: Contrast between high concession payments and high poverty rates in Eastern DR Congo

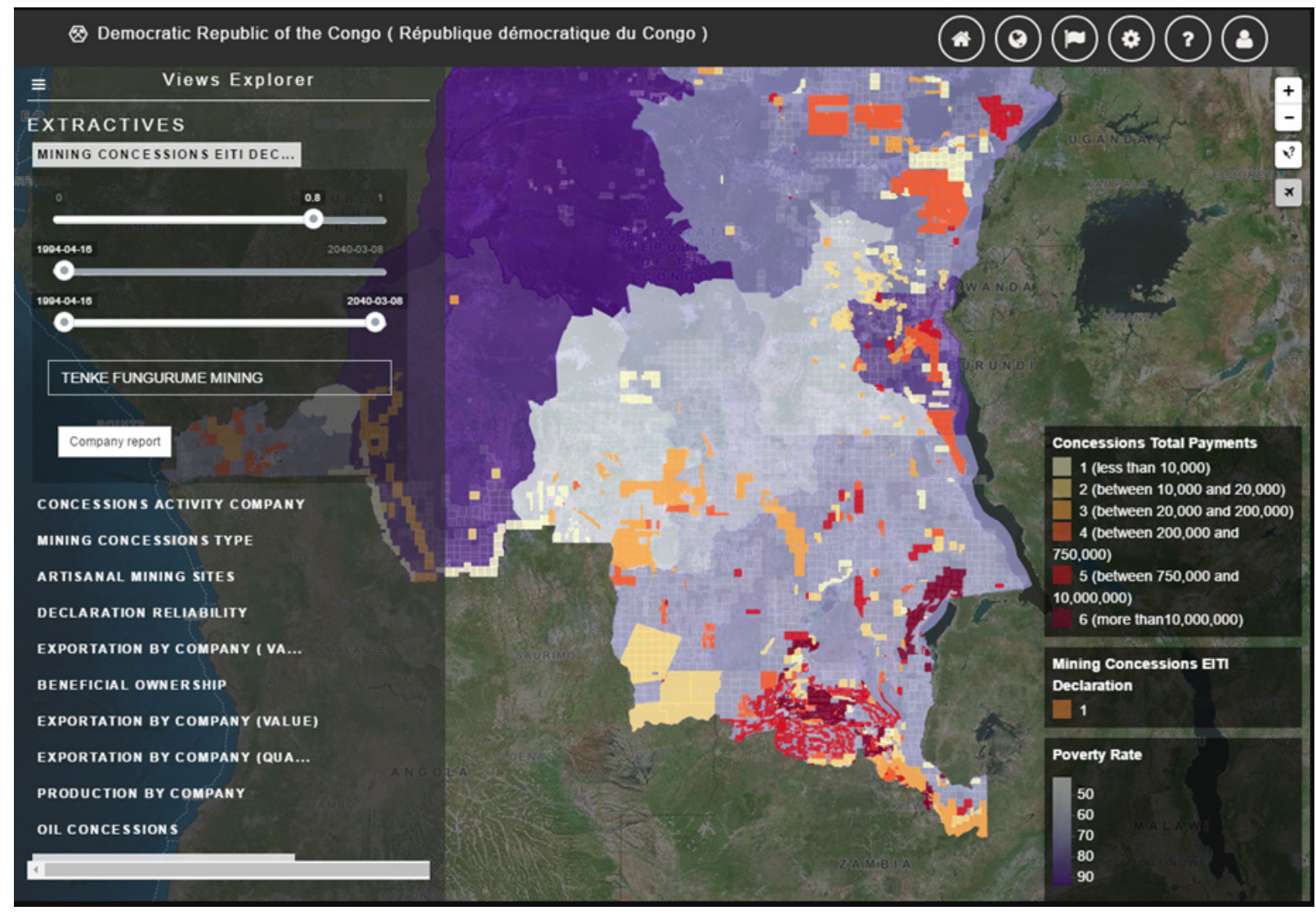

Source: EITI 


\section{Process}

The main organizations involved in the development of this tool were the Government of the DRC, the Extractive Industries Transparency Initiative (EITI), the United Nations Environment Programme (UNEP), the World Bank, the Global Resource Information Database (GRID-Geneva), and MapX. MapX is responsible for the development of the data catalog and hosts the online spatial data platform, which contains more than 50 layers. It enables multi-party data sharing and provides access to a range of datasets held by the government, private sector operators, academia, development partners, and local communities. It helps stakeholders identify potentially conflictual information to enable data rectification and reconciliation processes. It also provides independent authentication and quality monitoring of all national datasets through the implementation of the MAP-X data integrity framework. All the data can be accessed on the MapX platform in a secure data 'sandbox', a designated space in the platform where policymakers can securely upload, analyze, and visualize datasets without making them publicly available ${ }^{31}$.

\section{Impacts}

While not yet in place for long enough to measure impact, the hope is that the tool will:

1. Reduce information asymmetries among stakeholders and support evidence-based decision-making.

2. Help decision-makers and stakeholders understand the tradeoffs of different investment decisions.

3. Build trust and depoliticize environmental information.

4. Develop a more integrated understanding and planning of economic, social, and environmental impacts from extractive industry projects ${ }^{32}$.

\section{Ciudatos SDG Dashboard: SDG assessment that integrates perceptions}

\section{Objective}

Localizing the SDGs in Colombian cities is a multi-year initiative. It seeks to support the development of cities in Colombia through technical support and coordination of data and planning efforts. The SDG data tool has been developed in a way that it can be adapted to individual city contexts and includes a list of city-level indicators and targets.

This open data platform is an example of how cities can work together to improve and coordinate planning, track a common set of indicators, and integrate feedback from citizens. This platform not only includes government statistics, but also perception data. This is done through a survey which is rolled out on an annual basis in each city. ${ }^{33}$ Figure 12 shows the perception of the wellbeing of citizens in the city of Bogotá. It can be seen that since 2008 the number of respondents that are "somewhat dissatisfied" and "very dissatisfied" has increased. This trend should be cause for concern to the local government. 
Figure 12: Perception of wellbeing in Bogota (2008-2017)

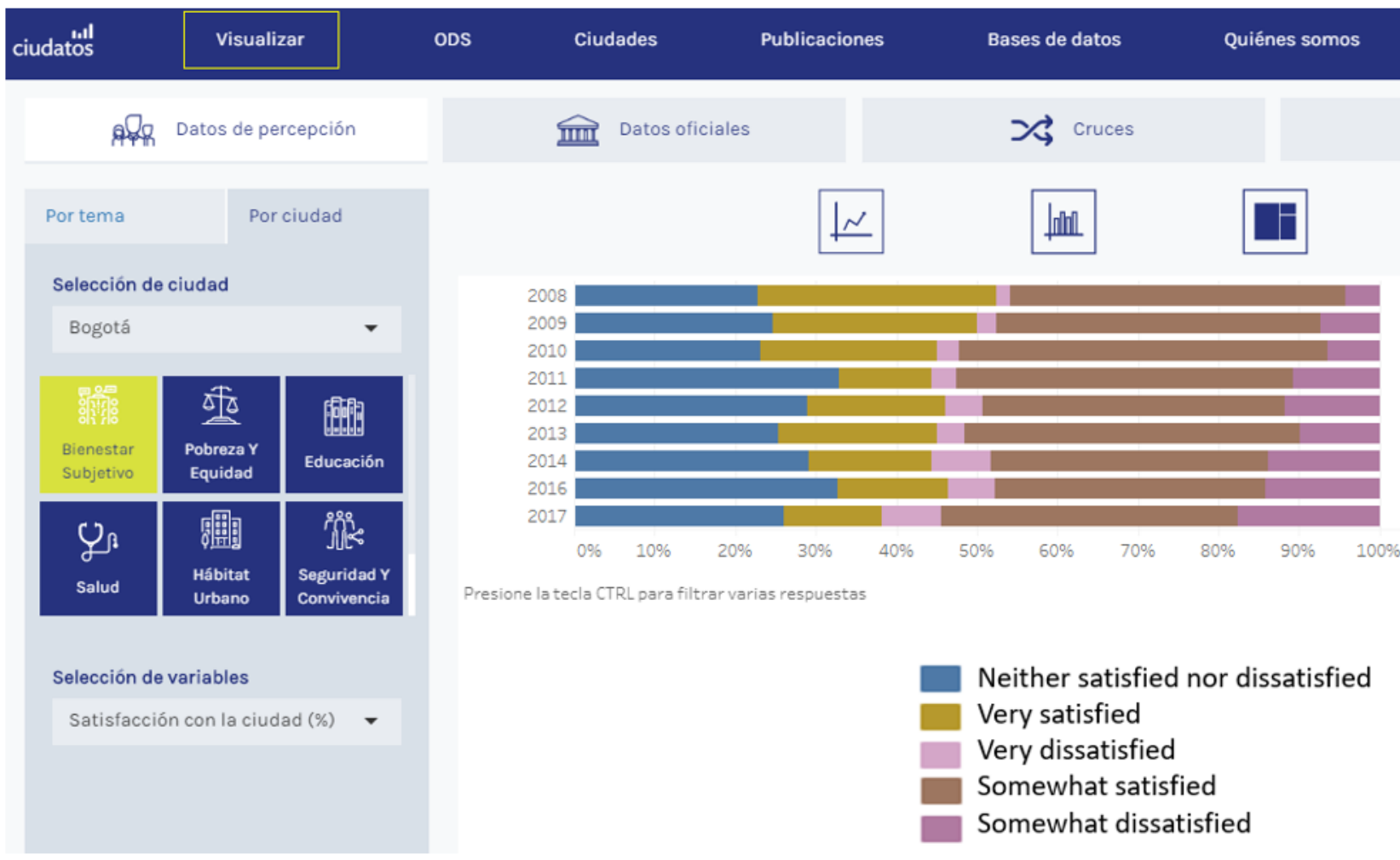

Source: Ciudatos

\section{Process}

The Cómo Vamos City Network (CVCN) was launched in 2017 and is the leading organization behind this initiative. It is responsible for managing the project and engaging civil society. The Colombian cities that are part of the network participated and contributed to developing the tool. The Dashboard has been designed to be easily accessible and user-friendly for citizens. The development of this tool is built on the idea that a centralized information platform with standardized indicators will be better positioned to successfully localize and align development plans with the SDGs. ${ }^{34}$

\section{Impacts}

This initiative has become an important management tool for local governments to align their development plans with the Agenda 2030, and to measure their progress towards achieving the targets. Because the tool can take into account differences in resources, capacity, and level of development of cities, it provides a framework that each municipality can adapt to its local context. Recognizing the differences and similarities of cities, in a national effort to achieve the SDGs, is fundamental, especially because capacities vary greatly depending on the territories.

In Colombia and all the cities of the CVCN, this effort has spurred the interest of the public, the private sector, and civil society to implement the Agenda 2030. The tool has helped to create a more active participation and monitoring process. Thereby, it has helped to increase accountability. ${ }^{35}$ 


\section{\#Business4SDGs - Business contributions to the SDGs}

\section{Objective}

The main goal of the \#Business4SDGs Dashboard is to track how the private sector contributes to achieving the SDGs in Papua New Guinea (PNG). Businesses that have invested in inclusive business practices and CSR initiatives can use the Dashboard to measure and track the impact of their work. It brings together data from government initiatives and budget allocations and merges it with data from companies collected through surveys. It presents a sustainability score for every business to see how it ranks against the SDGs. Recommendations are given to how companies could improve practices to support the SDGs. ${ }^{36}$

Figure 13: Business survey data

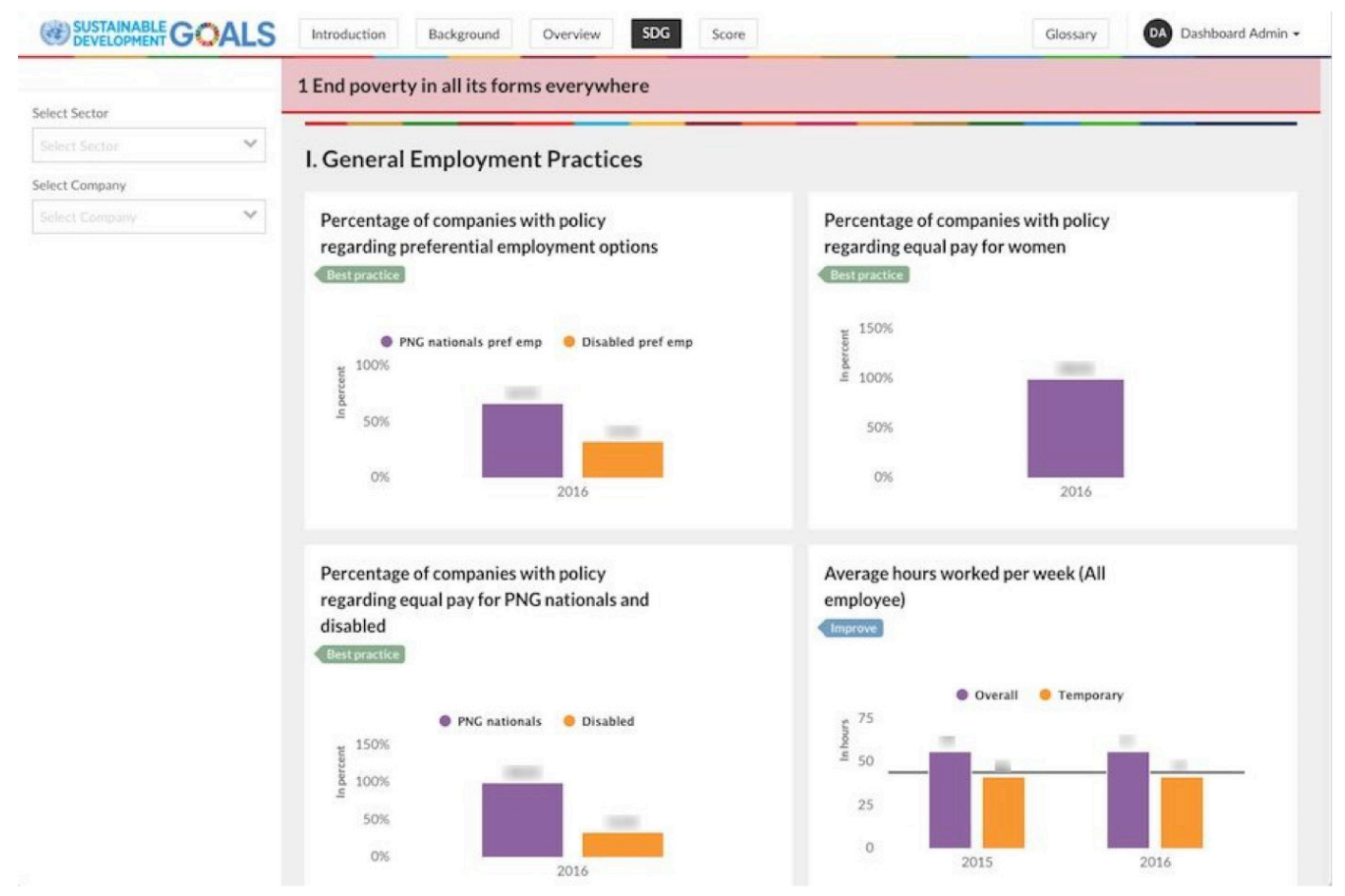

\section{Source: SocialCops}

Figure 13 shows the "Average hours worked per week" indicator, which is separated out for temporary workers and fulltime employees. In this particular example, there is room for improvement to have companies reduce the hours worked by their employees. 


\section{Process}

PNG did not achieve the Millennium Development Goals (MGDs). One of the identified reasons was the low involvement of the private sector. Private sector efforts were disconnected from government initiatives and there was a lack of coordination and knowledge sharing. Based on this conclusion, UNDP and the Business Council of Papua New Guinea partnered with SocialCops, a data intelligence startup based in New Delhi, to create the \#Business4SDGs Data Intelligence Dashboard. This solution was brought to life following six major steps:

1. Data aggregation: Construction of a database that tracks the country's development history with data that goes back to 1975.

2. Development mapping: Research on PNG's development interlinkages between budget expenditures and development outcomes.

3. Questionnaire design: Development of sector-specific questionnaires on companies' sustainability practices.

4. Data collection: Survey of six leading companies in PNG to collect granular data on internal practices and CSR initiatives.

5. Score development: Development of the Sustainability Score for companies.

6. Data visualization: Data Dashboard that makes it simple for businesses to monitor development metrics, company-level data, and Sustainability Scores. ${ }^{37}$

\section{Impacts}

The project is still in its infancy, and therefore, it is not possible to evaluate its impacts. However, it is hoped that this project will help the government, companies, civil society, and foundations to produce and share accessible and comparable data. This will allow for the different stakeholders to align their interventions, to better measure impact, and to improve interventions when outcomes are not as hoped. Furthermore, it will encourage the private sector to increase its contributions to achieve the SDGs. ${ }^{38}$

\section{MOABI DRC: Participatory monitoring}

\section{Objective}

Moabi DRC is a collaborative mapping initiative that aims to increase transparency and accountability of natural resources in the Democratic Republic of Congo (DRC). It aims to monitor REDD+ projects and strengthen the participation of civil society and local communities in monitoring natural resource management in the country.

Community members can share, edit, and discuss issues that could affect the sustainability of critical ecosystems. By linking grassroots groups working in the field to international organizations, Moabi seeks to build a global community that promotes transparency and sustainable resource use in critical ecosystems. It uses crowdsourcing to find and update information. Organizations and individuals working on forestry, mining, agriculture, and infrastructure projects can map and edit relevant spatial information. ${ }^{39}$ The figure below shows the exploration and exploitation permits for mining concessions and, in brown, the logging concessions. These can be overlaid with natural forest areas and protected areas to understand where there are overlaps. 
Figure 14: Mining and logging concessions

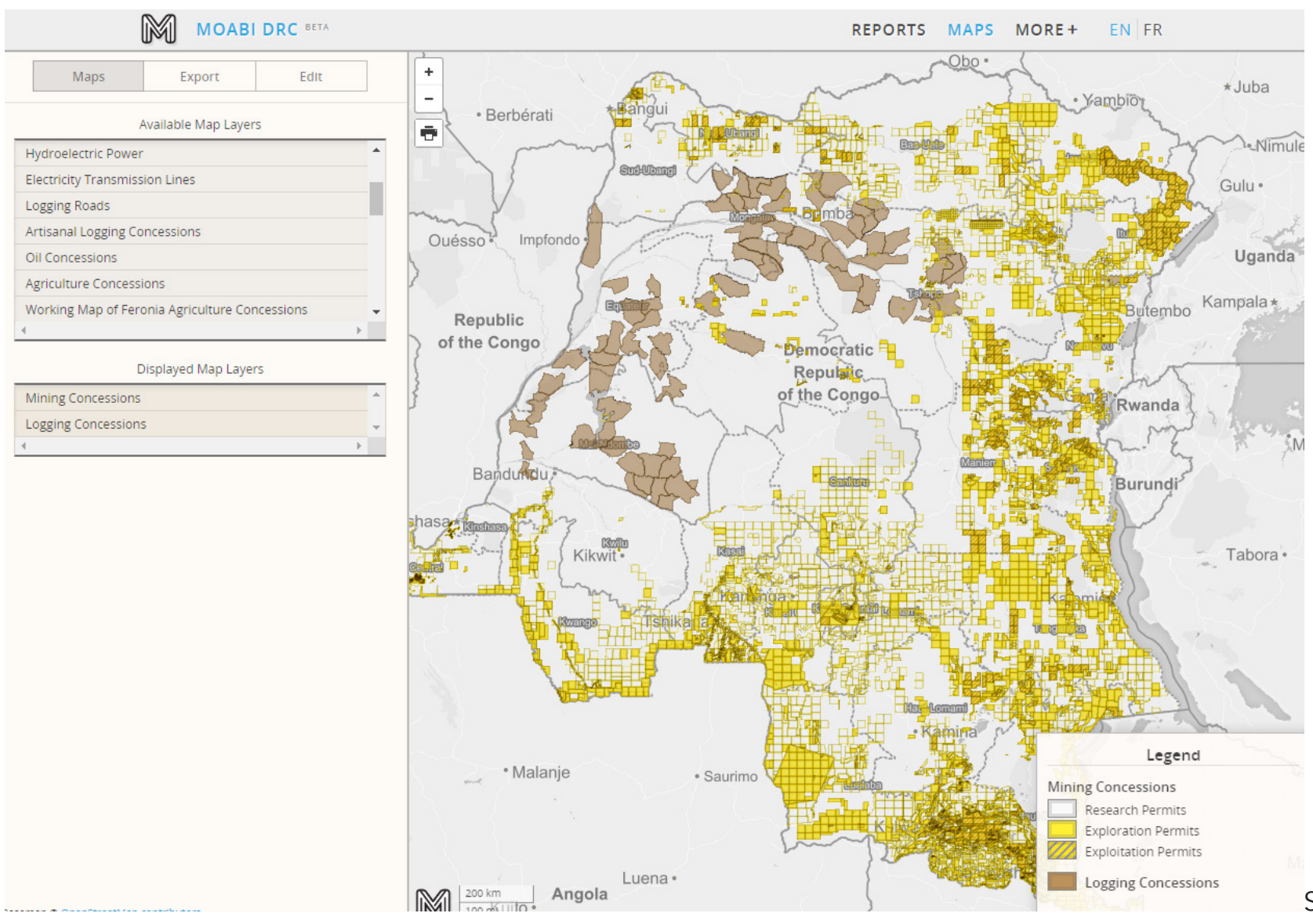

Source:

Source: Mabobi DRC

\section{Process}

In the development of Maobi DRC, Crowd Cover worked in partnership with the forest monitoring agency (OGF) of the DRC and a regional satellite monitoring institution (OSFAC) for central Africa.

The tool was launched in June 2011 by the World Wildlife Fund (WWF) and OSFAC. In 2013, the management of Moabi DRC was handed over to the International Institute for Applied Systems Analysis (IIASA) to improve forest governance through independent monitoring in the DRC. WWF DRC remains an active member of the Moabi DRC consortium and a key data contributor. ${ }^{40}$

\section{Impacts}

This project has strengthened the capacity of DRC civil society to conduct independent forest monitoring. It is the only platform that hosts civil society, government, private, and academic data on a single platform in the DRC. The project outputs have led to important dialogues around economic, social, and environmental tradeoffs in the country. Civil society organizations and donors rely on Moabi DRC as a reliable and up-to-date data source. ${ }^{41}$ 


\section{Dublin Dashboard: City tool with real-time environmental and transport data}

\section{Objective}

The Dublin Dashboard provides citizens, planners, policymakers, and companies with extensive information on Dublin City, including real-time data, indicator trends, inter and intra-urban benchmarking, interactive maps, the location of services, a means to directly report issues to city authorities, and links to city apps. ${ }^{42}$

One objective of the Dublin Dashboard is to answer questions related to what is happening in the city right now. To achieve this, the Dashboard collates, analyses, and presents real-time environmental and transport data. This is done via real-time maps that show the locations where data are recorded and indicates the current value of the variable being measured. ${ }^{43}$ Figure 15 shows the 16 locations where air quality is measured in Dublin with a map of the city overlaid in different colors depending on the value of the Air Quality Index for Health. The air quality in the figure ranges from purple (very poor air quality) to different grades of green (good air quality). During the time of the screenshot, the air quality in the city center was higher than in the suburbs.

Figure 15: Air quality map

\begin{tabular}{|l|}
\hline D Air Quality \\
\hline List of Air Quality Stations \\
\hline Air Quality Index for Health \\
\hline Reports \& Bulletins \\
\hline Local Air Quality Data \\
\hline What We Monitor \\
\hline Air Quality Plans \\
\hline Air Quality Standards \\
\hline Air Quality Zones \\
\hline For Health Professionals \\
\hline For Developers \\
\hline Air Enforcement \\
\hline
\end{tabular}

Air Quality Index for Health Map Legend
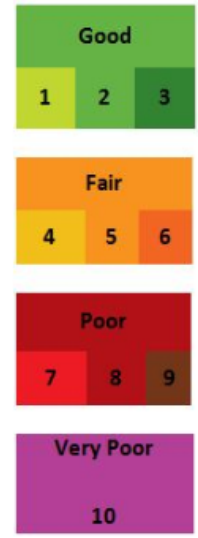

\section{Air Quality}

The Map below is coloured based on the current Air Quality Index for Health (AQIH) status. We welcome feedback on this update*

Click on your area of the map to see the AQIH for your region, click on the monitoring stations to show more information.

If an area of the AQIH map displays no colour, there may be an instrument or communication issue associated with that area.

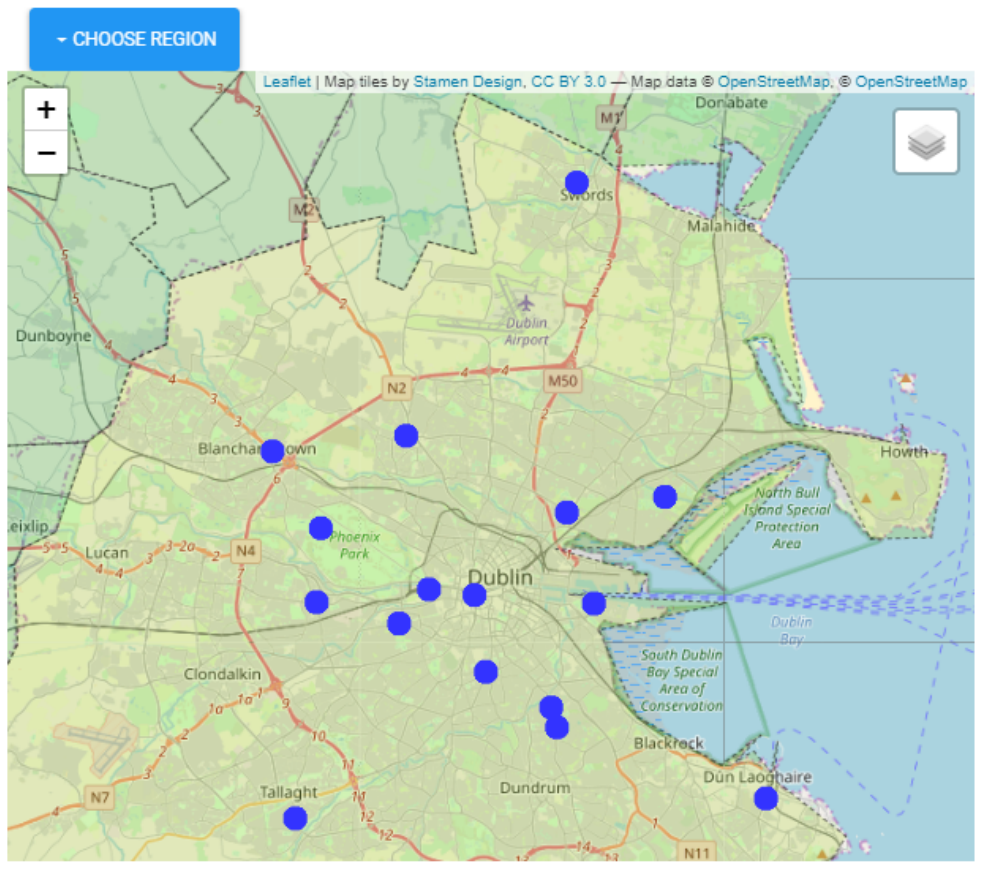

Source: Environmental Protection Agency 
The Dublin Dashboard consists of information captured in modules. The modules are a mix of bespoke applications, developed specifically for the project, and curated applications developed by others. ${ }^{44}$ The modules include: transport, environment, industry, employment, housing, health, and crime. Real-time data is shown for environmental and transport indicators. Links to relevant mobile applications, data sites, and reporting sites are also included. Citizens can report places in the city that are not working or need to be fixed. ${ }^{45}$

\section{Process}

The Dublin Dashboard is part of the European Research Council's (ERC) funded project "The Programmable City," which started in November 2013.46

The underlying data is drawn together from Dublin City Council, Dublinked, Central Statistics Office, Eurostat, and government departments. ${ }^{47}$ All the information on the Dashboard is freely available and users can do their own analysis and build visualizations.

\section{Impacts}

The Dublin Dashboard was made public in September 2014 and received much media attention. Feedback has been positive since then, with the public and enterprises supporting the initiative and seeking additional tools to be incorporated. It has become a tool for citizen engagement and has helped the local government in its decision-making processes. ${ }^{48}$

\section{Socio-Economic Technology Initiative ${ }^{49}$ : Community feedback mechanism for mining projects}

\section{Objective}

The main goal of the tool is to create a perpetual, common-evidence base that allows all stakeholders equal access to independently verified data and information to improve development planning frameworks around mine sites. The Socio-Economic Technology Initiative (SETI) platform is being developed to help deepen the understanding of the sentiments and likely responses of the workforce and communities to the issues that are impacting their lives. It is being designed to assist with measuring the likely impact of local, provincial, and even national economies, as well as offering a channel whereby problem-solving ideas and suggestions can be put forward by the communities themselves.

The tool is built on the premise that it is necessary to improve the possibility for communities to contribute directly to the debate and participate in the decision-making process regarding issues that are affecting their lives regularly in a structured manner and an atmosphere of trust. If communities are to be active participants in collaborative efforts to achieve consensus around key issues confronting the mining industry, inclusive communication needs to take place through better access to information as the foundation for meaningful dialogue. The SETI platform is intended to be used to interrogate possible scenarios in this regard.

The tool stands out due to its ability to seamlessly combine and co-join qualitative and quantitative data made accessible via visual and user-friendly interface on multiple devices. By harnessing new technologies for socio-economic development purposes, an opportunity exists to develop new decision-making tools that permit more complex and sophisticated analysis. This in turn enables consensus building around strategies for more effective social spending in the mining industry. The SETI Project is trialing the aggregation of existing knowledge and data from multiple sources, in multiple formats and applying innovative and advanced computing technologies that accelerate and enhance analytical processes at speed and scale. In so doing, the aim is to create a globally applicable resource or set of decision-making tools that will enable a unique analysis of socio-economic information pertaining to mining and its positive and negative impacts by all stakeholders in the industry. Due to the availability of data and the country's long mining history, the project is being incubated in South Africa with the intention of expanding to other countries. 


\section{Process}

For two years $\mathrm{MD} 360^{\circ}$ interrogated various commercial technology offerings to assess whether these could be adapted to build the envisioned platform around mine sites. However, none were able to provide the full solution envisaged. As such, a decision was taken to build the technology platform, which is currently in development. The platform is being constructed in three phases. The first module is the qualitative data ingestor, which is currently in beta testing through engagements with communities. The second module focuses on the quantitative data linkages to relevant social and economic data and is concurrently in design based on insights raised through the field trial. The third module is the visual interface for multiple users across various devices, which is yet to be developed.

Subject matter experts with extensive experience in social, economic, technology, and community development have been assembled to collaborate on the project. External data partners include the South African national statistics agency Statistics South Africa (StatsSA) and the South African National Space Agency (SANSA), which are contributing data and specialist expertise. The project is supported by the mining industry (Minerals Council of SA), academic institutions such as the Wits Mining Institute, and $\mathrm{MD} 360^{\circ}$ s strategic relationships with international organizations such as IISD (International Institute for Sustainable Development) and CIRDI (Canadian International Resources and Development Institute).

The tool is currently not publicly accessible as it is under construction with Module 1 (qualitative data ingestor) in beta testing. However, when complete, SETI will be open access and hosted in the cloud. Responsibility for system management and maintenance as well as data curatorship will rest with $\mathrm{MD} 360^{\circ}$.

Algorithms are being designed to isolate anomalies in the ingestion methods and there will be continuous systems testing as the data volumes build to reach a stable state. As an integral part of Module 1, provision is made for verification of issues raised and assertions made by respondents whose positions are captured through the qualitative data ingestion that forms the backbone of this module. System design will provide for appropriate feedback systems to ensure the veracity of information contained within SETI.

Figure 16: $\mathrm{MD} 360^{\circ}$ Dashboard

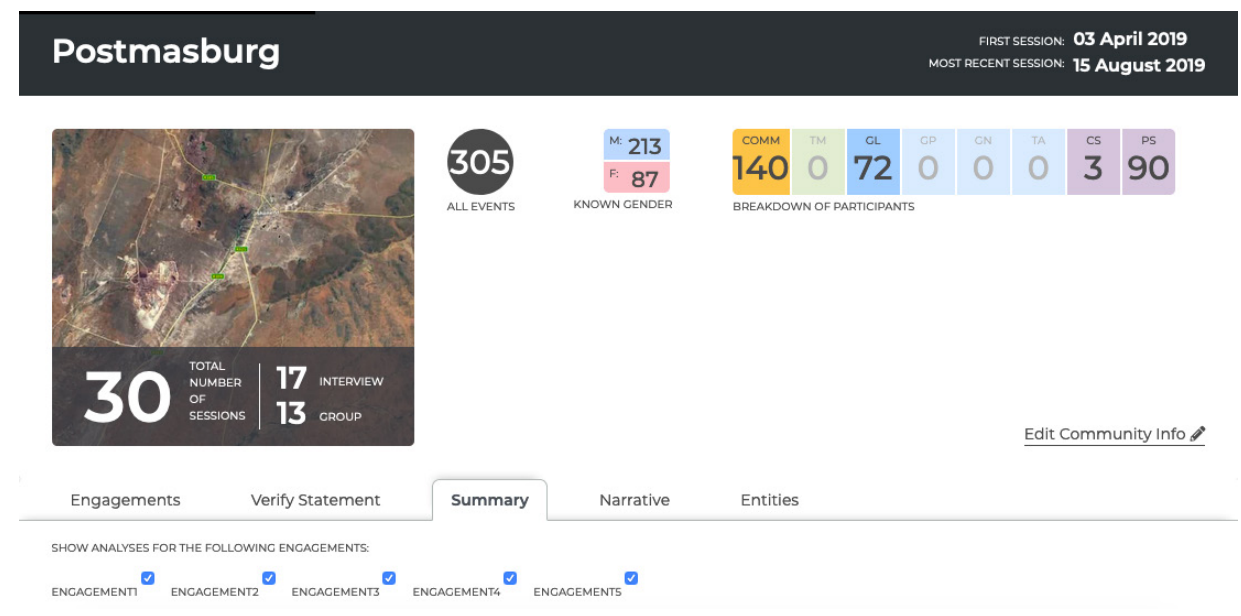

\section{Source: $M D 360^{\circ}$}

Figure 16 shows the beta version of the $360^{\circ}$ Dashboard. It shows that in this example 30 consultation sessions have been captured in the geographic location and that 305 events or qualitative inputs have been obtained from personal interviews and group meetings. From the interviewees, 213 were male and 87 were female. The breakdown of interviewees include community members (COMM), team members (TM), local government (GL), provincial government (GP), national government (GN), tribal authority (TA), civil society (SC), and private sector actors (PS). 


\section{Impacts}

While it is too early to measure impacts given that the project is still in its infancy, positive feedback has been received from a number of stakeholders in places where SETI Module 1 has been field tested. Feedback has been received that the tool has permitted access to greater insights into community opinion and sentiment compared to traditional means of consultation. This augurs well for the formulation of better-informed strategies for mine-community development.

\section{Endnotes}

Joseph Stiglitz, "Towards a New Paradigm for Development: Strategies, Policies, and Processes," Given as the 1998 Prebisch Lecture at UNCTAD, Geneva (October 19, 1998). Available at: http://web.worldbank.org/archive/ website01013/WEB/IMAGES/PREBISCH.PDF

For evidence on the sub-national resource curse see Jim Cust and Claudia Viale (2016). "Is There Evidence for a Subnational Resource Curse?”, NRGI Policy Paper https://resourcegovernance.org/sites/default/files/ documents/nrgi is-there-evidence-subnational-resource-curse.pdf CCSI (2016). Linkages to the Resource Sector - http://ccsi.columbia.edu/files/2016/07/Linkages-to-theresource-sector-GIZ-CCSI-2016.pdf.pdf Global Task Force of Local and Regional Governments, "Learning Module 1: Localizing the SDGs/ Introduction," (July 2017). Available at: http://localizingthesdgs.org/library/view/348 OECD, "Medium-term Expenditure Frameworks", in Government at a Glance 2013, OECD Publishing, Paris, (2013). Available at: https://doi.org/10.1787/gov glance-2013-27-en Minitoreo CDMX Platform is available at: http://www.monitoreo.cdmx.gob.mx/ Presentation given by Oliver Castañeda, General Coordinator for Administrative Modernization for the Government of Mexico City, in the 2018 UN-High Level Political Forum (July 15, 2018). Timor-Leste Aid Transparency Portal available at: aidtransparency.gov.tl

9 Sustainable Development Solutions Network, "Getting Started with SDGs in Cities: A Guide for local Stakeholders," (2016), pp. 42-43

10 Sustainable Development Solutions Network, "Getting started with SDGs in Cities: A Guide for Local Stakeholders," (2016), p. 52

Sustainable Development Solutions Network, "Getting started with SDGs in Cities: A Guide for Local Stakeholders," (2016), p. 47

Sustainable Development Solutions Network, "Getting started with SDGs in Cities: A Guide for Local Stakeholders," (2016), p. 49 (2015), pp. 30-31 PWC, "Making it your Business: Engaging with the Sustainable Development Goals," (2015). Available at: https://www.pwc.com/gx/en/sustainability/SDG/SDG\%20Research FINAL.pdf PWC, "Making it your Business: Engaging with the Sustainable Development Goals," (2015). Available at: https://www.pwc.com/gx/en/sustainability/SDG/SDG\%20Research_FINAL.pdf Initiative, (2014). Available at: https://sites.hks.harvard.edu/m-rcbg/CSRI/research/Costs\%20of\%20Conflict Davis\%20\%20Franks.pdf

CCSI, SDSN, UNDP \& WEF, "Mapping Mining to the Sustainable Development Goals: An Atlas," (2016). Available at: http://unsdsn.org/resources/publications/ mapping-mining-to-the-sustainable-development-goals-an-atlas/ Medellin SDG Public onsultation Platform is available at: https://public.tableau.com/views/ODS_Formulario/ Dashboard1?\%3Aembed=y\&\%3Adisplay_count=yes\&publish=yes\&\%3AshowVizHome=no ; 
22 State of Hawaii, "Aloha+ Challenge Recommendations for Taking Action and Tracking Progress", (2014).

23 Sustainability Business Forum. Available at: https://sbf.hawaiigreengrowth.org/

24 "Business Sector Energy Efficiency". Available at: https://dashboard.hawaii.gov/stat/goals/5xhf-begg/ fgyu-2f7k/5w9f-qicr

25 UCLG, "Monitoring the Global Agenda in Municipalities: The Mandala tool," (2018).

26 UNDP, "UNDP ART Initiative Territorial Partnerships for Implementing the SDGs at Local Level”, (January 2018).

27 Mandala ODS. Available at: http://ods.cnm.org.br/mandala-municipal

28 Correio, "A Agenda 2030 é a nossa Declaração Global de Interdependência", (September, 2019). Available at: https://www.correio24horas.com.br/noticia/nid/a-agenda-2030-e-a-nossa-declaracao-globaldeinterdependencia/

29 EITI, "Addressing the Challenges of EITI Mainstreaming: Observations from the Democratic Republic of Congo", (December, 2016). Available at: https://eiti.org/blog/ addressing-challenges-of-eiti-mainstreaming-observations-from-democratic-republic-of-congo MapX, "DR Congo: Extractive Industries Transparency Initiative Support", (December 2017). Available at: https://www.mapx.org/drc-eiti/

$31 \quad$ EITI, "Addressing the Challenges of EITI Mainstreaming: Observations from the Democratic Republic of Congo", (December 2016). Available at: https://eiti.org/blog/ addressing-challenges-of-eiti-mainstreaming-observations-from-democratic-republic-of-congo Lacroix, P et al. "MapX: An Open Geospatial Platform to Manage, Analyze and Visualize Data on Natural Resources and the Environment", (January 2019). TReNDS, "Localizing the SDGs in Colombian Cities with the Cómo Vamos City Network", (April, 2019). TReNDS, "Localizing the SDGs in Colombian Cities with the Cómo Vamos City Network", (April, 2019). Red Cómo Vamos, "Territorializando los ODS en las ciudades de Colombia”, (Octoberr 2019). SocialCops, "Tracking Businesses' Contributions to Achieving the SDGs". Available at: https://socialcops.com/ case-studies/undp-png-tracking-business-contribution-sdgs/

SocialCops, "Tracking Businesses' Contributions to Achieving the SDGs". Available at: https://socialcops.com/ case-studies/undp-png-tracking-business-contribution-sdgs/

UN India, "SocialCops And UN In India's SDG Dashboard Named Finalist of The First Ever United Nations SDG Action Awards”, (February 2018). Available at: https://in.one.un.org/un-news/ socialcops-un-indias-sdg-dashboard-named-finalist-first-ever-united-nations-sdg-action-awards/ WWF, "Moabi". Available at: https://www.worldwildlife.org/pages/moabi Moabi DRC, "The Platform". Available at: http://rdc.moabi.org/the-initiative/en/ Norad, "A Mapping Project Resulted in Improved Transparency and Civil Society Participation in Forest Governance in the Democratic Republic of Congo", (October 2013). Available at: https:// norad.no/en/front/funding/climate-and-forest-initiative-support-scheme/grants-2013-2015/projects/ improving-forest-governance-through-independent-monitoring-in-the-democratic-republic-of-congo/ The Programable City, "The Politics and Praxis of Urban Data: Building the Dublin Dashboard”, (April 2015). Available at: http://progcity.maynoothuniversity.ie/2015/04/ the-politics-and-praxis-of-urban-data-building-the-dublin-dashboard/ McArdlea, G, Kitchin, R. "Improving the Veracity of Open and Real-Time Urban Data”, (August 2015). McArdlea, G, Kitchinb, R. "The Dublin Dashboard: Design and Development of a Real-time Analytical Urban Dashboard”, (September 2016).

45 Dublin Dashboard. Available at: http://www.dublindashboard.ie/pages/index

46 Dublin Dashboard Launch Presentation, (September 2014). Available at: https://www.slideshare.net/ robkitchin/dublin-dashboard-launch

47 All Ireland Smart Cities Forum, "Dublin Dashboard", (May 2018). Available at: https://smartcitiesireland.org/ projects/dublin-dashboard/

48 McArdlea, G, Kitchinb, R. "The Dublin Dashboard: Design and Development of a Real-time Analytical Urban Dashboard”, (September 2016).

49 The information for this case study was provided to us by Mining Dialogues $360^{\circ}$, as the tool is not yet publicly accessible. 


\section{ccsi.columbia.edu}

Columbia Center on

Sustainable Investment

Jerome Greene Hall

435 West 116th Street

New York, NY 10027

Phone: +1 (212) 854-1830

Email: ccsi@law.columbia.edu
The Columbia Center on Sustainable Investment is a leading applied research center and forum dedicated to the study, discussion and practice of sustainable international investment.

Back Cover: Choapa Province, photo courtesy of AMSA

Design: Michael Morgan 